Review

\title{
Natural Killer (NK)- and T-Cell Engaging Antibody-Derived Therapeutics
}

\author{
Christoph Stein ${ }^{1, \dagger}$, Ingo Schubert ${ }^{2, \dagger}, *$ and Georg H. Fey ${ }^{2}$
}

1 Department of Experimental Medicine and Immunotherapy, Institute of Applied Medical Engineering, Helmholtz Institute, RWTH, Aachen 52074, Germany;

E-Mail: stein@hia.rwth-aachen.de

2 Department of Biology, University of Erlangen-Nuremberg, Erlangen 91058, Germany; E-Mail: gfey@biologie.uni-erlangen.de

$\dagger$ These authors contributed equally to this work.

* Author to whom correspondence should be addressed; E-Mail: ischuber@biologie.uni-erlangen.de; Tel.: +49-9131-85-28088; Fax: +49-09131-85-28082.

Received: 19 April 2012; in revised form: 21 May 2012 / Accepted: 24 May 2012 /

Published: 1 June 2012

\begin{abstract}
Unmodified antibodies (abs) have been successful in the treatment of hematologic malignancies, but less so for the treatment of solid tumors. They trigger anti-tumor effects through their Fc-domains, and one way to improve their efficacy is to optimize their interaction with the effectors through Fc-engineering. Another way to empower abs is the design of bispecific abs and related fusion proteins allowing a narrower choice of effector cells. Here we review frequently chosen classes of effector cells, as well as common trigger molecules. Natural Killer (NK)- and T-cells are the most investigated populations in therapeutical approaches with bispecific agents until now. Catumaxomab, the first bispecific ab to receive drug approval, targets the tumor antigen Epithelial Cell Adhesion Molecule (EpCAM) and recruits T-cells via a binding site for the cell surface protein CD3. The next generation of recombinant ab-derivatives replaces the broadly reactive Fc-domain by a binding domain for a single selected trigger. Blinatumomab is the first clinically successful member of this class, targeting cancer cells via CD19 and engaging T-cells by CD3. Other investigators have developed related recombinant fusion proteins to recruit effectors, such as NK-cells and macrophages. The first such agents currently in preclinical and clinical development will be discussed.
\end{abstract}


Keywords: NK-cell; T-cell; effector cell; tumor therapy; Fc receptor; bispecific antibody

\section{Introduction}

Antibodies (Abs) have evolved primarily for the defense against infectious agents, but not against spontaneous tumors of non-viral origin in mammals and man. Some cancer patients have specific abs directed against autologous tumor antigens, which may play a role in immune-surveillance, controlling the emergence of tumors by the immune-system [1-3]. The importance of immune-surveillance in the development of spontaneous tumors is still not fully understood [4,5], but the contribution of such auto-abs and of an adaptive immune response may be underestimated at present. To overcome past problems and to turn abs into more successful adjuvants for the treatment of tumors, it will help to modify the natural format of immunoglobulins (Igs) and to empower them for the task. In the past three decades several new formats of ab-derived agents have been developed for this purpose. One large group of new agents are ab-drug conjugates (ADCs). A variety of drug-components have been used in these compounds, ranging from bacterial- and plant-derived toxins such as diphtheria toxin, pseudomonas exotoxin A, saporins, and saponins, through chemically synthesized toxins such as maytansinoids, duocarmycins and auristatins, to human death effector proteins, including granzymes, caspases and RNases [6-9]. The first ADC to receive drug approval was gemtuzumab-ozogamycin (Mylotarg), a conjugate between a CD33-specific IgG and the toxin calicheamycin, which was effective in the treatment of acute myelogenous leukemia (AML). The agent was withdrawn from the market because of systemic toxicity [10-12], but newer more potent ADCs have been developed with reduced systemic adverse effects. Recently, Brentuximab vedotin, a CD30-directed ADC, was approved by the US Food and Drug Administration (FDA) for the treatment of Hodgkin's- and systemic anaplastic large cell lymphoma [13]. Trastuzumab emtansine (T-DM1) has shown positive results in a clinical phase III study for the treatment of breast cancer (NCT01120184), and several other ADCs are in clinical trials. Great expectations are placed on this group of agents, but there are some difficulties associated with their development, including problems with immunogenicity and manufacturing. A second large class of ab-derivatives attempts to recruit the body's own cells as effectors for the elimination of cancer cells. This approach offers several unique advantages, including a reduced immunogenicity and a greater ease of manufacture, and also appears attractive for the following reason: Often, some cancer cells resist the treatment with ADCs, and these may be either cancer stem cells (CSCs) with an intrinsic resistance to the drug, or cells with an increased resistance acquired by mutation. Gleevec-resistant cells of patients with chronic myelogenous leukemia (CML) illustrate the point [14]. However, such cells may still be susceptible to agents recruiting cytotoxic effector cells because the intracellular mechanisms, by which both classes of agents induce death in cancer cells, differ, and the mechanisms rendering cells resistant to both classes of agents are not the same. Therefore, it is reasonable to develop both types of new agents and to explore whether they may also be useful as components in combination therapies.

Several different classes of effector cells can be recruited by agents of this second group, and several different trigger molecules in each class of effectors are suited for the purpose. In this review 
we focus on agents recruiting effector cells for the elimination of malignant cells, in particular NK-cells and T-lymphocytes, because these have been widely studied. Other classes of effector cells, which have not yet been fully exploited, such as macrophages and neutrophilic granulocytes, also offer attractive potential for the design of ab-derived therapeutics for cancer, but will only be mentioned in passing.

A third way to improve efficacy of therapeutic abs is to optimize their Fc-domain for stronger binding to Fc-receptors (FcRs) on effector cells by Fc-engineering. This can be achieved either through introduction of point mutations at critical positions known to be important for the contact between Fc-domains and various types of FcRs from x-ray crystallography and other functional assays, or by glyco-engineering. A small number of point mutations is sufficient to greatly enhance the strength of binding Ig Fc-domains to various FcRs, including CD16 and CD64, and thereby improving cytotoxic function in ADCC (ab-dependent cellular cytotoxicity) assays, as well as phagocytosis through macrophages in ADCP (ab-dependent cellular phagocytosis) assays. An example of Fc-engineering by point mutagenesis is Xmab5574, a CD19 ab with improved binding to CD16a and CD64 by more than an order of magnitude, and correspondingly increased ADCC and ADCP functions [15]. This ab is scheduled for advancement to clinical trials in the near future. Another Fc-engineered CD19-ab has already been used for the treatment of leukemia patients with promising initial results. Glycoengineered abs with improved N-glycosylation patterns have shown improved binding to FcRs and improved functional properties [16]. In particular, the next generation of anticancer abs carrying afucosylated glycoforms is currently in clinical development [17]. The most advanced among these is the glycoengineered CD20 ab obinutuzumab (GA101), currently in phase II/III clinical trials for treatment of non-Hodgkin's lymphoma and chronic lymphocytic leukemia [18].

Due to stronger binding of optimized Fc-domains to FcRs, the competition of therapeutic abs with plasma Ig should be greatly reduced, and a greater fraction of the injected dose should reach the FcRs and mediate the desired effects [19]. Therefore, it is currently expected, that Fc-engineered abs will show improved therapeutic efficacy in upcoming clinical trials. In this review, however, we will emphasize ab-derivatives which deliberately recruit a chosen class of effector cells by engaging a trigger molecule present only on the desired subset of effectors, rather than relying on the broad range of effectors engaged by the reaction of abs still carrying an entire Fc-domain.

\subsection{Frequently Used Trigger Molecules and Classes of Effector Cells}

Anti-tumor effector functions mediated by abs include ADCC, ADCP, and complement-dependent cytotoxicity (CDC) [20]. The first two are mediated by the interaction of the Fc-domain with FcRs on the surface of effector cells, while CDC is triggered by interactions between Fc-domains and complement proteins. FcRs are expressed on leukocytes and some other cell-types, including endothelial and epithelial cells, and are divided into three groups: Fc $\alpha$-, Fce- and Fc $\gamma$-receptors. The major group of human Fc $\gamma$ Rs comprises five different members falling into three subgroups. Fc $\gamma \mathrm{RI}$ (CD64) is expressed on monocytes, macrophages, granulocytes and dendritic cells (DCs) and mediates ADCC, ADCP and most importantly, the clearance of immune complexes. Expression levels of CD64 are low on unstimulated granulocytes and DCs, and are increased by cytokines and growth-factors, including G-CSF [21]. FcyRII (CD32), a low affinity receptor for immunoglobulin G (IgG), exists as 
an activating (CD32a) and an inhibitory (CD32b) variant, products of two separate homologous genes, with distinct but partially overlapping cellular expression patterns [22,23]. FcyRIIa, mainly expressed on monocytes, neutrophilic granulocytes, and other myeloid cells, carries an immunoreceptor tyrosine-based activation motif (ITAM) in its cytoplasmic domain, and similar to CD64, mediates ADCP. After binding of IgG to CD32a, an oxidative burst is triggered in neutrophils and monocytes. The inhibitory CD32b is expressed on monocytes, other myeloid cells and B lymphocytes, but in two different allelic variants. Myeloid cells express the internalized B2 variant; B cells the non-internalized $\mathrm{B} 1$ variant. Co-ligation of membrane $\mathrm{Ig}$ with $\mathrm{CD} 32 \mathrm{~B} 1$ on B-cells inhibits signaling through the membrane Ig-receptor. As a result, the B-cell response to antigens, for which IgGs are already present, is dampened [24]. On plasma cells, CD32b regulates persistence and apoptosis [25], while on placental epithelial cells CD32 may play a role in the transport of IgG.

The third subgroup of Fc $\gamma$ Rs, are the low affinity Fc $\gamma$ RIIIs, comprising again an activating and an inhibitory variant. FcyRIIIa (CD16a), the activating transmembrane form, is expressed on NK-cells, macrophages and mast cells, and mediates ADCC [15,26]. CD16b is expressed on human neutrophilic granulocytes. On human cells, this variant is linked to the cell surface by glycosyl-phosphatidyl inositol (GPI), and does not transmit signals into the cells, because it lacks a signal-transducing cytoplasmic domain [27-29]. CD32b therefore acts as an inhibitory receptor, because the numerous neutrophilic granulocytes deplete the pool of soluble, available IgG. Two types of the FceR are known: the high affinity FceRI is present on Langerhans cells, eosinophils, mast cells, basophils and antigen presenting cells [30-32]. This receptor plays a role in allergic responses and the production of cytokines. FceRII (CD23) is a low affinity receptor for IgE present on B-cells, eosinophils and Langerhans cells [33]. CD89, the sole receptor for IgA (FcaR), is constitutively expressed on monocytes, macrophages and neutrophilic granulocytes [34]. Stimulation of these cells by occupation of the Fc $\alpha \mathrm{R}$ with IgA results in potent ADCC and ADCP [35], and this effect has not yet been mined extensively for therapeutic purposes.

Due to the clinical success of therapeutic abs, interest in the recruitment of effector cells has markedly risen over the past 20 years. The interaction of the Fc-domain with FcRs is important to mediate therapeutic effects, but, in vivo, this interaction is often unsatisfactory [27]. The unmodified Fc portion of an ab binds to several types of FcR on a number of different cell types, including cells other than the desired effectors. This may result in a strong reduction of the available pool of soluble abs for therapeutic effects by depletion of the injected dose. Furthermore, the therapeutic ab competes for binding to FcRs with a large excess of existing plasma Ig in the patient. FcRs on the relevant effector cells are already occupied when the therapeutic ab arrives. To win this competition and to compensate for the losses by absorption through FcRs on non-relevant cells, the therapeutic abs need to be injected in high doses, which can be disadvantageous both due to infusion-related complications and from an economic point of view. An example in case are the large doses of the therapeutic CD20 $a b$ rituximab needed for an effective treatment of lymphoma, which are in the range of $10 \mathrm{mg} / \mathrm{m}^{2}$ and above per dose. Finally, binding to the inhibitory forms of FcRs may dampen rather than strengthen the desired therapeutic effects and cause still other unknown and unfavorable effects on the systemic immune response. To overcome these disadvantages it is helpful to specifically direct the agent to the effector cell of choice. Therefore, recombinant proteins with specific binding moieties for trigger molecules on particular types of effector cells have been developed [29]. The most commonly used 
trigger molecules for the recruitment of effector cells are the activating Fc $\gamma$ Rs, the Fc $\alpha$ R, and CD3 or CD28 on T-cells. A synopsis of these triggers and other modulators of the immune-response used for therapeutic purposes, as well as the effector cell populations carrying them is given in Table 1.

Table 1. Trigger molecules on different populations of effector cells.

\begin{tabular}{ll}
\hline Effector cells & Trigger molecules \\
\hline T-cells & CD3, TCR $\alpha, \beta$, CTLA4, PD1, CD28 \\
NK-cells & CD16a, NKG2D, NKp30, NKp40, LFA1 \\
Monocytes & CD89, CD64, CD32a, CD16a \\
Macrophages & CD89, CD64, CD32a, CD16a \\
Neutrophilic Granulocytes & CD89, CD64, CD32a \\
\hline
\end{tabular}

TCR, T-cell receptor; NKG2D natural killer cell lectin-like receptor gene 2D product. CTLA4, PD1, CD28, cell surface proteins on T cells with regulatory function after ligand binding. NKp30, NKp40, LFA1 activating cell surface receptors on NK cells.

\subsection{Examples of ab-Derived Agents Recruiting Effector Cells Other than NK-and T-Cells}

Molecules with a binding domain for FcyRI (CD64) are capable of recruiting macrophages, monocytes and G-CSF-stimulated granulocytes as effectors; the latter obtained either from G-CSF-treated patients or by ex vivo treatment of cultured granulocytes with this factor (Figure 1). A bispecific $\mathrm{F}(\mathrm{ab}$ ')-fragment and a bispecific ab targeting HER2/neu and engaging Fc $\gamma \mathrm{RI}$ have caused potent lysis of ovarian and lung cancer cells in vitro, mediated by cytokine-activated granulocytes [28,36]. Using a panel of bispecific $\left.\mathrm{F}(\mathrm{ab})^{\prime}\right)_{2}$ molecules in mice transgenic for human CD64, which were xenotransplanted with various lymphoma-derived human cell-lines, Honeychurch and colleagues obtained potent anti-tumor activity in vivo, mediated mostly by macrophages [37]. These observations were further extended by studies with a bispecific (Fab') $)_{2}$ and a recombinant tandem diabody targeting CD30 and engaging CD64-positive effectors, which induced ADCC and ADCP of human lymphoma-derived cells in cell culture assays by recruiting monocytes and macrophages [38,39]. Another bispecific $\mathrm{F}(\mathrm{ab})_{2}$, targeting CD19 and engaging CD64-bearing effectors, mediated efficient lysis of malignant B-lymphoid cells by recruiting interferon $\gamma$-primed macrophages. The effect was further enhanced, when the macrophages were pretreated with a combination of interferon $\gamma$ plus macrophage colony stimulating factor (M-CSF) [40].

Because of these encouraging preclinical results, three CD64-engaging agents were tested in clinical trials. The first was a F(ab') 2 targeting CD30 on Hodgkin lymphoma cells. This agent was tested in 10 patients with refractory lymphoma in a phase I trial, and one complete plus three partial remissions were observed [41]. The second agent, a bispecific $\mathrm{F}(\mathrm{ab})_{2}$ targeting the epidermal growth factor receptor (EGFR), MDX-447, was tested in 64 patients with kidney and head-and-neck cancer, but no objective responses were seen [42]. The third was a $\mathrm{F}(\mathrm{ab})_{2}$, targeting the tumor antigen HER2/neu (MDX-H210). In a pilot trial with 13 patients with advanced carcinomas, this agent was well tolerated with adverse effects limited to the days of infusion [43]. In a phase II study with MDX-H210 plus G-CSF in HER2/neu-positive prostate cancer patients, this agent showed clinical activity with acceptable side effects [44]. Thus, CD64-engaging agents may have an attractive, so-far barely-tapped therapeutic potential. Their development is not advanced as far as that of agents recruiting T-cells or 
NK-cells, possibly because the results obtained so far were not as convincing as those obtained with other ab-derived agents, and maybe also because there are reservations among drug-developing investigators against macrophages and granulocytes as effectors. Although both are potent classes of effector cells, macrophages may eliminate cancer cells mainly via phagocytosis, and this may be considered by some drug-developers as not as efficient as the elimination by the induction of cell death via apoptosis, necrosis or autophagy, which is induced by the directly cytolytic classes of effector cells. This perception is probably misguided, as shown by new data discussed below. Similarly, some preconceived concerns also persist, that granulocytes engaged as effectors may release a number of pro-inflammatory mediators, and that the resulting "mediator-storm" may be more detrimental than beneficial. However, these concerns are not based on strong supporting data, and these perceptions are likely to change in the future, as soon as such engaging agents are actually tested, as suggested by the recent findings for macrophages discussed below.

Figure 1. Elimination of tumor cells decorated with an ab-derived therapeutic protein via the recruitment of effector cells. Depending on the type of effector cell and the chosen trigger molecule, the mode of action can be either antibody dependent cellular cytotoxicity (ADCC), antibody dependent cellular phagocytosis (ADCP), or a cytotoxic T-cell reaction. The depicted cytotoxic agents are a monoclonal $\mathrm{ab}$, a bispecific chemically coupled $\mathrm{F}(\mathrm{ab})_{2}$, a recombinant bispecific tandem single-chain $\mathrm{Fv}$-fragment (bsscFv), and a trispecific tandem single chain triplebody (sctb).

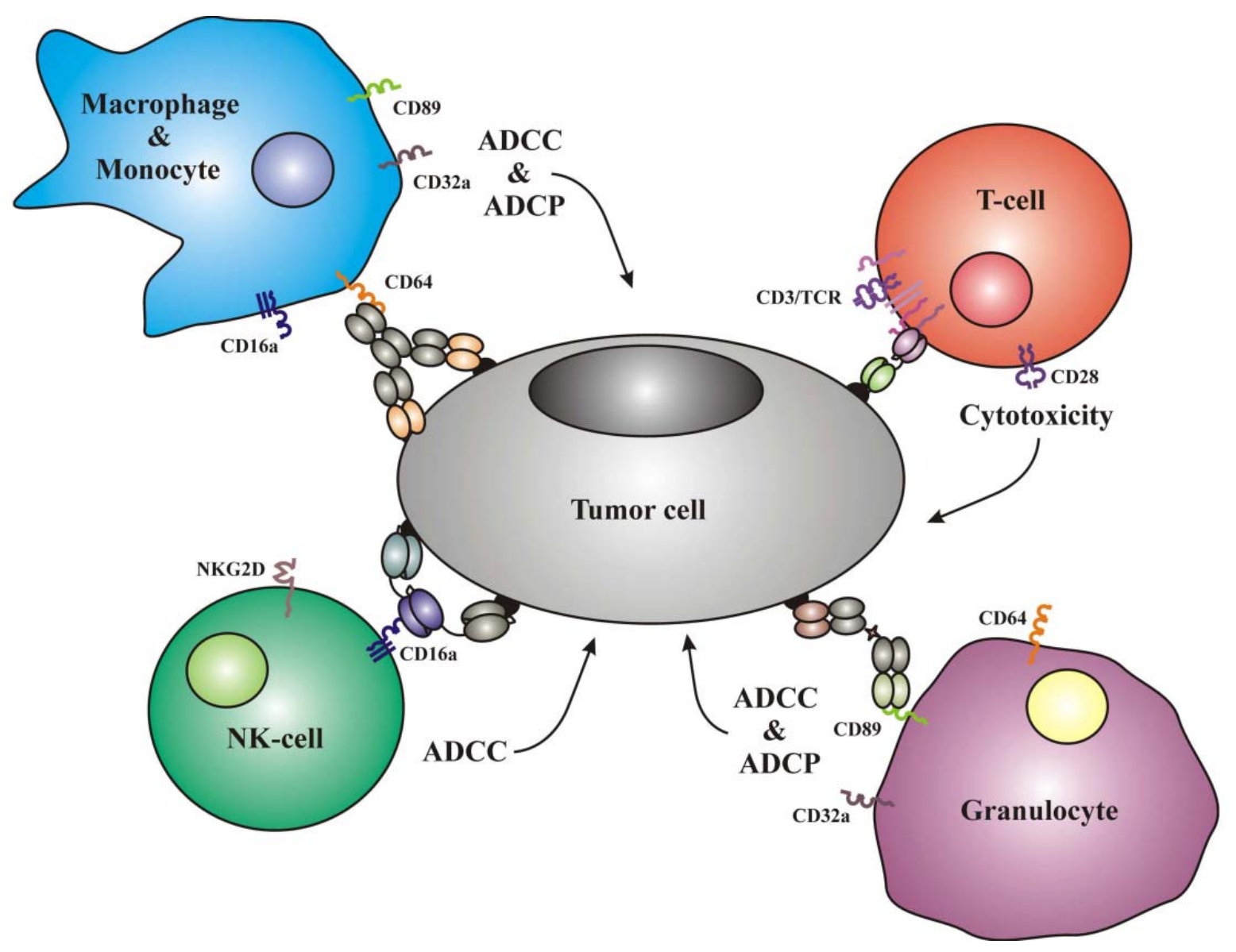


To demonstrate the potential of molecules engaging neutrophilic granulocytes and monocytes through the Fc $\alpha \mathrm{R}$ (CD89), three examples are discussed. The first are $\left.\mathrm{F}(\mathrm{ab})_{2}\right)_{2}$ conjugates targeting the tumor antigens HER2/neu or CD30, respectively. The second is a bispecific ab targeting the EGFR, and the third a tandem bispecific single chain Fv (bsscFv) targeting HLA class II [39,45-47]. All of these agents mediated $\mathrm{ADCC}$ in vitro by recruiting $\mathrm{CD} 89$-positive effector cells, i.e., mainly neutrophilic granulocytes and monocytes. No in vivo data are available, but CD89-transgenic mice exist and could be used for animal studies $[48,49]$. Although the cytolytic responses in cell culture assays were unusually potent [39], and although there is some promise for future clinical use of such agents, CD89-engaging agents have not been advanced very far into clinical development, probably for similar reasons as those given above for the lack of clinical development of CD64-engaging agents. Some drug developers anticipate that the contribution to the overall therapeutic effect by monocytes may be minor, and others fear that neutrophilic granulocytes may produce more undesirable side effects through the cytokines they release than beneficial effects. These fears however are not supported by convincing clinical data, and therefore, agents engaging CD64- and CD89-bearing effectors may still show therapeutic benefit, once tested in clinical trials.

Macrophages as effectors deserve to be further explored, in particular for tumors, where tumorassociated macrophages (TAMs) are present, which is the case for many solid tumors. In many cases TAMs have a tumor-supporting function, and may even promote the spawning of metastases [50-52]. TAMs favor tumor development by contributing to the remodeling of extracellular matrix and by the release of factors that promote cell proliferation, angiogenesis, and migration. They are capable of phagocytosis in principle, but their phagocytotic attack on tumor cells is blunted, because all patientderived tumor cells analyzed in recent studies carried a cell surface protein, CD47, a repressor of macrophage phagocytosis [52-54]. This happens by an interaction between CD47 and a ligand on macrophages and DCs, the Signal Regulatory Protein $\alpha$ (SIRP $\alpha$ ). After binding of CD47 to this ligand, signals are transmitted from SIRP $\alpha$ to the macrophage, which inhibit phagocytosis. CD47 has therefore been called a "don't eat me" signal. For survival and metastasis of tumor cells it is of paramount importance that they should avoid elimination by tumor-infiltrating phagocytes, and therefore it is not surprising, that CD47 is highly expressed on all tumor cells tested. Consequently, abs blocking CD47 had an antitumor-effect and prevented the formation of metastases in mouse models. "Given that TAMs are present in large numbers within tumors, CD47-directed ab-therapy may therefore have the potential to restore TAM immune surveillance and fundamentally alter the role of macrophages in the progression and survival of tumors" [52].

Interestingly, treatment with this blocking CD47 ab did not promote the phagocytosis of normal cells to an equal extent, although normal cells also display CD47, however in lower surface densities than tumor cells. From these findings Chao and colleagues [55] inferred that blockage of the inhibitory signals mediated through CD47 and SIRP $\alpha$ may have exposed a second signal present on tumor cells, but not on normal healthy cells, which actively promotes phagocytosis. In the absence of CD47-SIRP $\alpha$ signaling, healthy cells would therefore not be subject to phagocytosis. This second signal, also called an "eat-me" signal, has recently been identified and is caused by interaction of the tumor cell component calreticulin with the LDL-receptor 1-related protein (LRP) on macrophages [56]. This signal is required for the phagocytosis of tumor cells after blocking the CD47-SIRP $\alpha$ interaction. 
Calreticulin is present on the surface of a subset of cells in all human leukemias, lymphomas, and solid cancers, but not on non-tumor cells [57].

Therefore, one might envisage, that bispecific ab-derived reagents targeting calreticulin on the tumor cell and engaging macrophages through either FcRs or LRP, or even tri-specific ab-derivatives such as single-chain triplebodies [58,59] engaging both of these triggers simultaneously, may become an option for attractive new ab-derived therapeutics. Although this approach may encounter some difficulties due to the presence of calreticulin on some healthy cells, these new possibilities for the engagement of TAMs as effectors are a surprising development, because there was a bias against attempts to engage TAMs for the elimination of cancer cells, in view of the fact that their activities are mostly tumor-promoting. These new data indicate that even tumor-promoting TAMs can be converted into potent anti-tumor effectors, as soon as they are physically linked to tumor cells via therapeutic abs.

Another example in case, where macrophages play an important role in tumor biology, are follicular lymphomas. In lymph node follicles, where clonal expansion of B-cells takes place, vast numbers of macrophages are present and remove excess B-cells, and large numbers of macrophages are also present in hypercellular lymph nodes of follicular lymphoma patients. Therefore ab-derived agents engaging the infiltrating macrophages as anti-tumor effectors may also be a promising new avenue, in spite of the fact that in the absence of such agents the macrophages may play a tumor-promoting rather than an anti-tumor role. Similar concepts may become valuable for other tumors such as prostate- and ovarian cancers and several others, where TAMs are abundant [60].

A variety of bispecific ab-derived agents deliberately recruiting subsets of effector cells have been evaluated in clinical studies for different malignancies to date. The best-studied examples are summarized in Table 2. The majority of these agents recruit T-cells as effectors, and so far only one bispecific recombinant molecule engages CD16a on NK-cells and human macrophages.

Table 2. NK- and T-cell recruiting recombinant antibodies in clinical trials.

\begin{tabular}{|c|c|c|c|c|c|}
\hline Specificity & Format & Disease & $\begin{array}{l}\text { Development } \\
\text { status }\end{array}$ & Company & Trial \\
\hline CD19, CD3 & BsscFv & NHL, B-ALL & Phase I/II & Amgen & $\begin{array}{l}\text { NCT01207388, } \\
\text { NCT00274742 }\end{array}$ \\
\hline EpCAM, CD3 & BsscFv & Various tumors & Phase I & Amgen & NCT00635596. \\
\hline CEA, CD3 & BsscFv & $\begin{array}{l}\text { Gastrointestinal } \\
\text { cancers }\end{array}$ & Phase I & Amgen & NCT01284231. \\
\hline EpCAM, CD3 & Hybrid IgG & $\begin{array}{l}\text { Ovarian and } \\
\text { gastric cancer, } \\
\text { malignant } \\
\text { ascites }\end{array}$ & $\begin{array}{l}\text { Phase II/market } \\
\text { approval }\end{array}$ & Trion & NCT00464893 \\
\hline $\begin{array}{l}\text { HER2/neu, } \\
\text { CD3 }\end{array}$ & Hybrid IgG & Breast cancer & Phase II & Trion & NCT00522457 \\
\hline $\mathrm{CD} 20, \mathrm{CD} 3$ & Hybrid IgG & $\begin{array}{l}\text { B-cell } \\
\text { lymphoma }\end{array}$ & Phase I/II & Trion & NCT01138579 \\
\hline CD30, CD16a & TandAb & $\begin{array}{l}\text { Hodgkin } \\
\text { lymphoma }\end{array}$ & Phase I/IIa & Affimed & NCT01221571 \\
\hline
\end{tabular}




\section{Redirecting NK- and T-Cells for Cancer Therapy}

\subsection{T-Cells as Effectors for Cancer Therapy}

T-cells are activated by the interaction of the $\mathrm{T}$ cell receptor (TCR) with specific peptides loaded onto major histocompatibility (MHC) proteins present on other cells. For a strong T-cell reaction a co-stimulatory signal generated by the cross-talk between e.g., CD28 on the T-cell and its counterstructures CD80 (B7.1) or CD86 (B7.2) on antigen presenting cells (APCs) is needed [61]. Following stimulation through the TCR, T-cells produce Interleukin-2 (IL-2), which drives them into proliferation and differentiation. Apart from activating receptors, T-cells also express inhibitory surface proteins, which are important for the regulation of their responses. The cytotoxic T-lymphocyte antigen-4 (CTLA-4), an inhibitory surface receptor, binds with higher affinity to CD80 and CD86 than $\mathrm{CD} 28$, and thus promotes the inactivation of T-cells [62,63]. Another negative regulator is the receptor Programmed Death-1 (PD-1). After binding to its ligands on the interacting cell, signaling through PD-1 leads to T-cell anergy and apoptosis.

\subsubsection{Optimization of T-Cell Activity}

To counteract these effects, different experimental approaches have been taken. In 2011 the CTLA4-directed ab Ipilimumab was approved by the FDA for the treatment of patients with advanced melanoma. Ipilimumab binds CTLA-4 and prevents the interaction with its ligands. As a consequence, T-cells remain highly active and participate in anti-tumor functions, probably elicited by autologous tumor antigens and a break in tolerance. This was demonstrated in a clinical study, where Ipilimumab was administered either alone or in combination with a peptide fragment of glycoprotein 100 (gp100) to patients with metastatic melanoma. The patients treated with the combination had a significantly longer overall survival (10.0 months) than patients treated with gp100 alone (6.4 months) [64]. Melanoma patients frequently carry T-cells with a TCR specifically reactive with the tumor-antigen gp100, which has therefore been used for tumor vaccination in clinical trials of melanoma therapies. The expectation underlying this approach was that by enhancing the response of CD8-positive cytotoxic T-cells with specificity for gp100, the vaccination may have a therapeutic benefit through the increased elimination of gp100-bearing melanoma cells. In addition, it was anticipated, that through this vaccination an indirect contribution to the systemic anti-tumor response would be generated by causing a gp100-specific CD4-positive helper T-cell-, and thus an adaptive B-cell response [64]. The surprising finding was that this approach was therapeutically beneficial. After many years of rather modest success with tumor vaccination for melanoma [65], investigators had become pessimistic about its potential clinical benefit. Melanoma tumors are probably also driven by cancer stem cells (CSCs), and melanoma CSCs have greatly reduced MHC-I levels [66,67]. Therefore, the T-cell response elicited by the vaccinating peptides would be expected to have only minor effects on the melanoma CSCs, and thus would not be expected to have long-lasting therapeutic effects due to a reduction of this compartment. However, the reduction in the MHC-I-positive bulk melanoma cells achieved by this approach was apparently sufficient to cause the observed extension of overall survival, even if there may have been only a minor impact on CSCs. The clinical benefit was sufficient to deserve drug approval, and it compares well with the improvement in overall survival achieved by other therapeutic 
abs used in the treatment of other types of malignancies, which is often far less than the extra 4 months gained in this case. Treatment with this ab caused immune-related adverse events in approximately $10-15 \%$ of the patients compared to $3 \%$ of patients treated with gp100 alone, and there were several deaths in this study associated with immune-related adverse events. Therefore, treatment with this ab must have removed inhibitory signals from a broad range of T-cells and thus generated a broadly reactive set of hyperactive $\mathrm{T}$-cells, some of which may have caused the auto-immune complications and the noted immune-related adverse events. These events were severe in some cases, long-lasting, or both, but most were reversible with appropriate treatment. Considering the dismal alternatives for patients with metastatic melanoma, the clinical benefit achieved by this agent was sufficient to merit drug approval and the agent is now in routine clinical use. It is one of the very few successful treatments for metastatic melanoma, even if the success may be considered modest $[64,68]$.

Another mab, specific for PD-1, produced promising initial results as a single agent in clinical trials for the treatment of various solid tumors resistant or refractory to other treatments [69]. The rationale for the use of this ab was similar to the one described above for the CTLA- 4 ab. Further, a bispecific tandem scFv, specific for two different epitopes of CTLA-4, augmented rather than inhibited the activation of T-cells [70]. This approach may become useful in clinical applications where a boost of immunity is needed. In addition, Curran and colleagues reported that a combined blockade of CTLA-4 and PD-1 has lead to an increased level of infiltrating T-cells and the rejection of melanoma cells in vivo $[71,72]$. Another attempt to increase T-cell activity consists in triggering these cells via binding of an ab specific for CD137, a co-stimulatory receptor on T-cells and a member of the tumor necrosis factor (TNF) family. Ab-binding to CD137 promotes the proliferation, survival and cytokine secretion of T-cells, and CD137-specific abs were successful in vivo and produced promising anti-tumor effects $[73,74]$.

In 2006 a phase I safety study of the CD28-specific mab TGN1412 (TeGenero) was conducted with eight healthy volunteers [75,76]. Surprisingly, severe adverse events occurred, caused by a treatment-induced cytokine storm. Further analysis revealed that the starting dose for this trial was too high, due to the fact that this dose had been calculated from safety studies in primates. However, the primate leukocytes employed in these safety studies reacted far less strongly with this particular ab than corresponding human leukocytes. Therefore, in spite of this regrettable incident, CD28 remains a valuable target for an ab-mediated control of T-cell functions in vivo, and it continues to be developed for this purpose. A bispecific ab directed against melanoma-associated proteoglycan 2 (NG2) and CD28 has since been found to mediate cytotoxic T-cell effects only in the presence of NG2-positive tumor cells [77]. Interpreted in mechanistic terms, these results probably indicate, that triggering of $\mathrm{T}$ cells by binding of an ab for CD28 alone did not lead to a potent cytolytic response for melanoma cells, but that connecting the tumor cell with the effector through an immunologic synapse mediated by the agent caused far stronger cytolysis. This effect does not appear surprising, in view of published observations, that other bispecific ab-derivatives such as a bsscFv addressing CD19 and CD16, caused far stronger cytolytic effects mediated by NK cells, than a simple control ab specific for CD19 [58,78].

One potential explanation of these findings is that a T-cell releasing its toxins into the synaptic cleft produced by the bispecific agent generates a far greater local concentration of the toxic component in the cleft than a T-cell releasing its toxins in all directions of space in the absence of a synapse. Another tentative explanation is that once formation of the synapse is initiated by the bispecific ab, then other 
surface receptors of the T-cell and their counter structures on the target cell interact, tighten the synapse, and generate additional second signals which enhance the cytotoxic effect. Such secondary effects clearly exist for NK cells. When these cells form a synapse with their targets, then not only NK-cell receptors such as CD16 are activated, which trigger degranulation of cytotoxic granules and the release of their contents (e.g., granzymes). In addition, other receptors such as LFA1 are triggered by formation of the synapse, which cause a polarization of the effector cell, i.e., a relocation of the cytolytic granules into the direction of the synapse before degranulation [79]. This second signal in turn leads to an increased dose of toxins released into the synapse, and thus to a stronger cytotoxic effect. Whether analogous second signals are also important for the cytolytic synapses formed by T-cells and for the degranulation of these cells is unknown to us, but we assume that this is the case. Finally, we suppose that other apoptosis-, necrosis- or autophagy-inducing signals may be sent into the target cell as a consequence of the multiple interactions between the target and effector cell in the synapse. Such signals could be generated for example by the interaction of death receptors (CD95, Apo-1; Fas; TRAIL-receptors, TNF-receptors and others) with their ligands. Thereby, apoptotic pathways such as caspase- and/or mitochondrial paths to death can be induced in the target cell. Finally, necrosis and autophagy, other important paths to induced cellular death, may also be induced by similar second signals.

T-cells can indeed be recruited for the lysis of cancer cells by signals involving ligands for death receptors on the tumor cells. De Bruyn, Bremer, Helfrich and colleagues studied a series of intriguing fusion proteins for this purpose [80,81]. Two of these carried scFv-components specific for either CD3 or CD7 on the surface of T-cells, fused to the soluble TRAIL ligand, sTRAIL. These proteins, called anti-CD3:TRAIL and K12:TRAIL, bind CD3 or CD7, respectively, on the T-cells and through their sTRAIL component also bind the death receptors TRAIL R1 and TRAIL R2 (DR4 and DR5) on the surface of tumor cells. This interaction and the resulting aggregation of the TRAIL receptors on the surface of the tumor cells mediates cytotoxicity, which is far stronger for the cancer cells than for normal healthy cells of the organism, which also carry the same TRAIL receptors. It is not fully understood, why occupation of these receptors on tumor cells with the T-cell bound ligand causes apoptosis far more potently than engagement of the same receptor on healthy normal cells, but this surprising effect has been confirmed by other teams. As a result, the tumoricidal activity of T-cells was greatly enhanced. When T-cells were decorated with these agents and then assayed for cytotoxicity in cell culture ADCC assays, the tumoricidal activity for cancer cell lines and primary patient-derived malignant cells was increased by more than 500-fold compared to the control T-cells not decorated with these agents. Delivery of these proteins to T-cells also strongly inhibited tumor growth in mice and increased the survival time of mice xenografted with human tumor cells by more than 6-fold. An added interest in this class of targeted death-ligands comes from the fact, that certain leukemia stem cells (LSCs) have also been reported to carry elevated levels of TRAIL R1 and TRAIL R2, and probably can be sent into apoptosis by ligation of these receptors $[82,83]$.

\subsubsection{Recruiting T-Cells via CD3}

T-cells do not carry activating Fc-receptors. Therefore they cannot be stimulated directly by the Fc domain of an $a b$ and cannot be recruited for the direct elimination of a tumor cell by ab-mediated 
cellular cytotoxicity (also called "redirected lysis"). Major efforts have been made to overcome this shortcoming. One possibility is the use of bispecific ab-formats such as recombinant tandem bispecific scFvs, bispecific diabodies and tandem bispecific diabodies. Fusion proteins in these formats can specifically bind both the tumor cell and a trigger molecule on a T-cell. Many molecular formats with different combinations of specificities have been tested [84]. Suitable T-cell triggers, which induce cytotoxicity, cytokine release and an inhibition of proliferation, include CD2, CD3, CD5, TCR $\alpha$, $\mathrm{TCR} \beta, \mathrm{TCR} \gamma \delta$ and $\mathrm{CD} 28$. The best-studied trigger is CD3. After engagement of this receptor, cytotoxic T-cells are stimulated, causing the elimination of the target cell [85]. The most prominent member of this novel class of recombinant Bispecific T-cell Engagers (BiTEs) is the CD19- and CD3directed agent blinatumomab (MT103), which is studied in five ongoing clinical trials. It showed a very high cytotoxic potential in cytolytic assays in vitro with half-maximum effector concentrations (EC50) in the picomolar range, at a low effector-to-target cell (E:T) ratio of 2:1, without the need for co-stimulation of the T-cells [86]. MT103 was further successful in vivo as a mono-therapeutic agent in children with acute lymphoblastic B-cell leukemia (B-ALL) and in adults with Non-Hodgkin-Lymphoma, it mediated a complete remission and a prolonged leukemia-free survival, respectively [87-89].

First generation BiTEs still have a few minor shortcomings. One of these was an involvement of the central nervous system (CNS) leading to transient seizure-like symptoms in a small number of treated patients [87]. These events were rare, clinically manageable, and do not represent a serious obstacle against clinical use of the agent, because they mainly occurred when higher doses of the agent were used, than those now employed in routine clinical applications. Such symptoms were not observed when children with acute leukemia were treated with effective doses of the agent [90]. One possible interpretation is that T-cells decorated with this agent may have penetrated the blood-brain barrier and then caused the CNS symptoms. There may be a connection with earlier observations finding occasional CNS symptoms also in transplant recipients treated with the immunosuppressive CD3 antibody OKT3. The symptoms may therefore be associated with the use of CD3 as the particular trigger rather than with the general format of BiTEs.

A minor inconvenience associated with the use of this BiTE is its short plasma retention time (plasma half-life), which is on the order of less than one hour in humans. This is likely due to the low molecular mass of the agent, which is below $60 \mathrm{kDa}$. Therefore, the majority of the drug most likely is excreted upon first pass through the kidney. As a consequence, the agent is administered in multiple repeat doses and occasionally by continuous infusion using a portable pump. This however is only a minor inconvenience considering the potent therapeutic effect of the agent. If needed, this shortcoming can be alleviated by applying one of several available half-life extending techniques. One of these would be to couple the agent to polyethylene-glycol (PEG), a method used for half-life extension of other common drugs [91]. Another option would be to fuse the agent to fragments of human serum albumin (HSA) or albumin binding ab-fragments, and thereby improve the plasma half-life [92]. Finally, the BiTE format can be extended by adding a third ab-derived scFv binding site, thus generating a tandem single-chain triplebody. This extension increases the molecular mass beyond the kidney exclusion threshold and doubled plasma retention times in mice [58]. Therefore, the minor disadvantages of the BiTE format can be addressed in a satisfactory manner, and this novel class of agents represents major progress, because it is the first new class of recombinant ab-derived agents, which deliberately recruit a chosen class of effector cells, and which do not carry the broadly reactive 
Fc-domain of full-length Igs. It thereby avoids the problems linked to the presence of an Fc-domain. Consequently, these agents can be administered in far lower concentrations than full length Igs. Clinically effective doses of blinatumomab are in the range of $10 \mu \mathrm{g} / \mathrm{m}^{2}$ compared with effective doses of rituximab, which are in the range of $10 \mathrm{mg} / \mathrm{m}^{2}$, i.e., approximately one thousand-fold greater. Therefore, far lower systemic side effects are expected, the treatment might be better tolerated by the patients, and due to the lower cost of goods the drug will likely be more economic. Other advantages of the BiTE format need to be stressed. These agents can engage a wide range of T-cells, regardless of the specificity of their TCR, because CD3 is universally present on all cytotoxic T-cells. Thus large numbers of T-cells are available for recruitment. Approximate numbers of different classes of leukocytes circulating in healthy adult humans are shown in Table 3.

Table 3. Numbers of different classes of human leukocytes in healthy adults.

\begin{tabular}{ll}
\hline Cell type & Leukocytes per $\boldsymbol{\mu L}$ blood \\
\hline T-cells & $300-900$ \\
NK-cells & $120-350$ \\
Monocytes & $200-600$ \\
Macrophages & - \\
Granulocytes & $1800-7000$ \\
\hline
\end{tabular}

Adapted from [93].

Healthy humans carry approximately 3-times more T-cells than NK-cells in their circulation. T-cells can further proliferate after suitable stimulation, such as exposure to IL-2, and therefore their numbers may be sufficient to eliminate most cancer cells after recruitment by BiTEs. This numerical relation is often quoted as an advantage of the BiTE format over other formats of ab-derivatives recruiting CD16positive effectors, which are present in lower numbers in circulation. However, NK-cells, can also proliferate after suitable stimulation, and they may also be available in sufficient numbers locally at the tumor site for particular tumors, such as in the bone marrow of acute myeloid leukemia (AML) patients. Therefore, a mere look at the total numbers of these effector cells present in the periphery of a healthy human body may not convey an adequate picture of the number of effector cells available at the relevant tumor sites. Furthermore, when it comes to eradicating CSCs, which is required for the elimination of minimal residual disease (MRD) and the achievement of long-lasting therapeutic effects, then it may not be the quantity of the available effector cells, which is the dominant variable, but their quality. Conceivably, an NK-cell may have better access to a CSC residing in a stem cell niche than a T-cell, or function better in the hostile hypoxic environment of MRD sites than a T-cell. Therefore, it would be premature to judge the anticipated therapeutic potency of these new agents solely based on the number of available effector cells in the periphery of a healthy body. Still, T-cells have a far greater intrinsic toxicity than NK-cells on a per-cell basis, and T-cell infiltrates are present in many solid tumor tissues. Prominent examples are melanoma tissues, and therefore, T-cells appear to be a natural choice of effectors for the treatment of melanomas.

Other members of the BiTE-family, which are in pre-clinical or clinical studies, are specific for carcino-embryonic antigen (CEA), EpCAM, CD33, HER2/neu, EGFR and the melanoma-specific chondroitin-sulfate proteoglycan (MCSP), also called High Molecular Weight Melanoma Associated Antigen (HMW-MAA) [94-100]. The MCSP-reactive BiTE was less potent in in vitro cytolysis 
experiments than expected [94]. One possible explanation is that the chondroitin sulfate proteoglycan moiety was so bulky that it prevented the formation of an effective synapse between the effector and the target cell, mediated by the agent.

Catumaxomab (Removab ${ }^{\circledR}$ ), a hybrid Ig with specificities for CD3 and EpCAM, was recently approved for the treatment of malignant ascites [101,102]. One half of this chimeric Ig comes from a murine Ig and the other from a rat IgG. A second trifunctional antibody (ertumaxomab) of similar design, specific for CD3 and HER2/neu, showed first promising results in vitro and in vivo [103,104]. The in vitro study showed that effector cells isolated from the blood of patients with head-and-neck carcinoma after chemotherapy and radiotherapy were still able to eliminate HER2/neu- or EpCAMpositive tumor cells in the presence of ertumaxomab or catumaxomab, respectively. Hence, effector cells from patients can be recruited and activated after standard cancer treatment and can then be engaged by this agent to eradicate tumor cells. Problems associated with agents of this class are the relative difficulty in manufacturing such hybrid Igs, and their elevated immunogenicity in humans, due to their origin from two different rodent species.

Another new means to selectively engage T-cells for cancer therapy is a recombinant fusionprotein, consisting of an $\mathrm{scFv}$ component binding $\mathrm{CD} 3$ and the extracellular part of the activating NK-cell receptor Natural Killer cell lectin-like receptor Gene 2D protein (NKG2D). This agent binds cancer cells carrying the NKG2D ligand on their surface via its NKG2D component, and T-cells via its CD3 binding site. In vitro this chimeric agent successfully engaged T-cells and caused an efficient redirected lysis of NKG2D ligand-positive tumour cells. In a murine lymphoma model, the protein significantly promoted survival, and the tumour-free surviving mice were resistant to re-challenge with the relevant autologous tumour cells, suggesting the successful generation of a specific immunological memory response [105]. An adaptive immune-response of the host (including $\gamma \delta \mathrm{T}$ cells) was an essential component of the overall therapeutic effect of this agent. This fusion protein also reduced the pool of myeloid-derived suppressor cells and of regulatory $\mathrm{T}$-cells $\left(\mathrm{T}_{\text {reg}}\right)$, and increased $\mathrm{T}$-cell infiltration in the tumor tissue. These data invite the exciting interpretation, that the agent may have targeted these immune suppressive cells, because these also carry the NKG2D ligand [106]. This new chimeric protein is intriguing, because it is one of few reported cases, where a secondary systemic immune response after treatment with an immunotherapeutic agent has been documented, and where this secondary response was an integral and essential part of the therapeutic effect. We suspect, that the same may also have occurred for several of the other new agents discussed above, but that it has not been studied and not been recorded in those cases as systematically as for this agent.

Another fusion protein, consisting of a recombinant engineered T-cell receptor specific for peptides derived from gp100 and presented by HLA A2, and a CD3-specific scFv, has been advanced into a phase I clinical trial for malignant melanoma (NCT01211262). Finally, Lum and colleagues investigated the use of activated T-cells from cord blood as a cellular therapeutic, armed ex vivo with bispecific abs targeting CD20 or HER2/neu on the one side, and engaging CD3 on the other [107]. Cordblood MNCs were first incubated ex vivo with an anti-CD3 mab and IL-2, to activate and expand the T-cells. The expanded T-cells were then armed ex vivo with bispecific mabs and successfully used in ADCC-experiments in vitro. They had low alloreactivity and therefore adoptive transfer of these decorated cells may be an attractive possibility to reduce graft-versus-host disease (GVHD) and to simultaneously enhance the anti-tumour effect. A phase I clinical trial with autologous, CD20 $\times$ CD3 
mab-armed and activated T-cells for the treatment of patients with relapsed or refractory NHL is currently ongoing (NCT00521261).

\subsection{NK-Cells for Cancer Therapy}

NK-cells have both an innate ability for the direct killing of tumor cells ("natural killer activity"), and the ability to mediate ADCC after being recruited by ab-derived agents [79,108]. These two modes of action differ greatly, and the dramatic changes in the function of an NK-cell, which are introduced after engagement via an ab-derived agent, are often not sufficiently stressed. Once an ab-derived therapeutic is brought into play, which directly connects the target cell with the NK-cell through a trigger receptor such as an FcR, the situation changes profoundly. In the absence of abs and ab-derived agents, the activation of NK-cells depends on the balance of activating and inhibitory signals triggered by surface receptors. In the presence of ab-derived agents this balance is greatly altered, and the relative influence of the inhibitory receptors is greatly diminished. Activating receptors include the family of natural cytotoxicity receptors: NK30p, NK44p and NKp46, as well as NKG2D, 2B4, NKp80, CD16 and CD226 [109]. The group of inhibitory receptors comprises members of the killer cell immunoglobulin-like receptor (KIR) superfamily (KIR2DL1, KIR2DL2/3, KIR3DL1, KIR3DL2), as well as siglec7/9 and NKG2A [110]. In the presence of an activating signal (but in the absence of an ab-derived agent), the inhibitory ligands can suppress the "natural" cytotoxic NK-cell function [111]. However, when a tumor cell is connected with an NK-cell by engagement of a trigger molecule via an ab-derived agent, then the release of granzymes and INF- $\gamma$ occurs in spite of inhibitory signals and overpowers the latter [112-114]. This function is called an "ADCC reaction" or "redirected lysis" and is no longer the same as the "natural killer activity". This change from "natural killer mode" to "ADCC mode" is similarly profound, as the total reversal of the function of TAMs after addition of an anti-CD47 ab, which reprogrammed the macrophage from a tumor-promoting to a tumor-eliminating cell (section 1.2 above) [115]. This change from the "natural killer mode" to the "ADCC mode" by ab-derived agents is illustrated in Figure 2.

In their "natural killer mode" NK-cells play a role in the in the immunosurveillance of neoplastic cells $[117,118]$ and they are also used in this mode in cancer therapy [119]. This is routinely the case in the context of stem cell transplantation in tumor therapy, for example in leukemia therapy. Here, NK-cells are regenerated from the transplant, and participate in the graft-versus-leukemia response. The effect can further be strengthened by additional adoptive transfer of enriched NK-cells, and this is frequently used in the post-transplant treatment of both adult and pediatric patients with acute leukemia [120-124]. This use of NK-cells as cellular therapeutics trough transplantation and/or adoptive transfer is an entirely different therapeutic modality from the recruitment of resident NK-cells through the administration of therapeutic anti-tumor abs, the focus of the present paragraph, although both effects can be combined. 
Figure 2. The presence of an ab-derived agent in an NK-cell reaction dominates the inhibitory signals which govern the "natural killer" reaction. Target cells were CD19-positive cryo-preserved blasts from pediatric patients with a pre-B/common ALL (acute lymphoblastic leukemia), labeled with europium. Effectors were immune-magnetically enriched CD56-positive NK-cells from unrelated healthy donors. $2 \mathrm{~h}$ BATDA europium release assay. Specific lysis is total lysis minus spontaneous release (in the absence of added NK cells). Left column: specific lysis obtained after the addition of a chimeric CD19 antibody with an Fc portion from a human IgG1. Second column from left: lysis obtained with NK cells alone, in the absence of any added ab ("natural kill lysis"). Lytic activity is greatly reduced, due to KIR inhibition. After addition of an anti-HLA-I ab or ab Fab-fragment of this ab, the KIR inhibition is lifted, due to blockage of HLA-I on the target cells (3rd and 4th columns from the left). The fact that the de-repression also occurred with the Fab-fragment of the HLA-I $a b$, and not only with the intact ab demonstrates, that the recovered cytotoxicity was not due to an ADCC effect via the Fc-domain of the HLA-I ab, which decorated the target cells, but was due to blocking of HLA-I. Comparison with the left-most column shows, that after addition of the CD19 ab, "ADCC lysis" was equally strong as the "natural kill lysis" with blocked HLA-I, although in this case, no HLA-I blocking ab was added. This result illustrates the important claim, that through addition of an ab engaging the NK-cell via its FcRs, the KIR inhibition is overruled. From Lang 2004 [116] with permission. This research was originally published in Blood. (C) the American Society of Hematology.

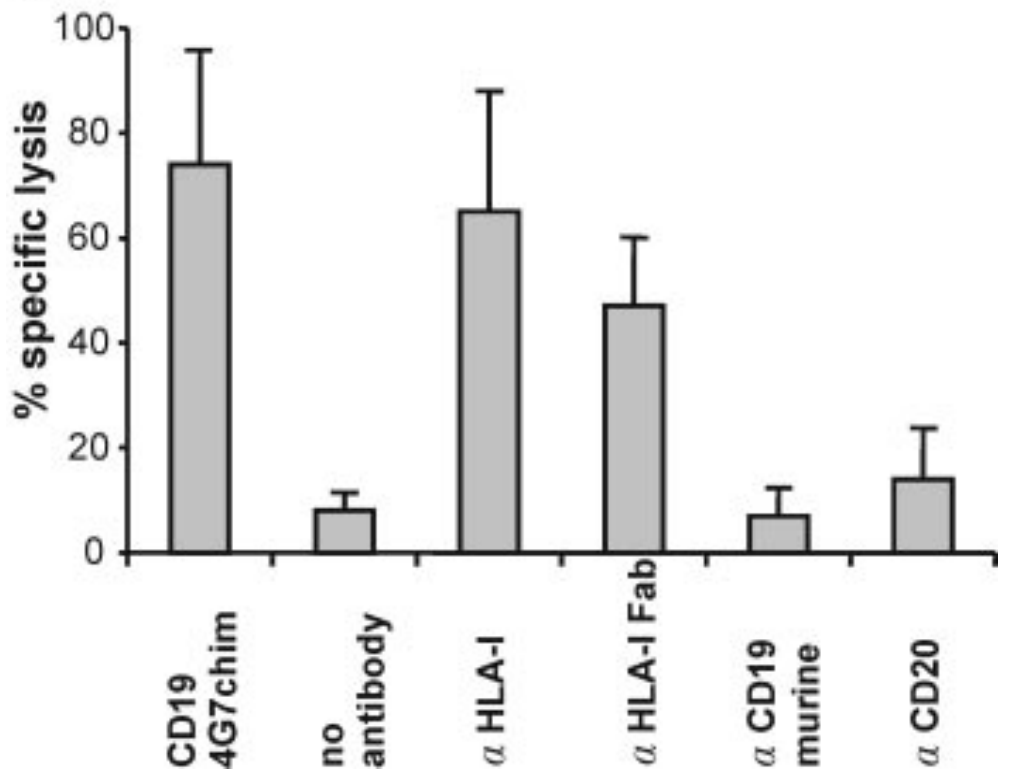

\subsubsection{Recruitment of NK-Cells by Anti-tumor Abs}

Every therapeutic ab probably mediates a unique spectrum of cellular responses in vivo. For example, the CD20-ab Rituximab activates complement in vivo, recruits NK-cells, macrophages, and possibly other myeloid cells, and indirectly probably also DCs and B-cells for a secondary humoral response. It is difficult to dissect the exact spectrum of responses occurring in a human organism after 
treatment with an ab-derived agent, and to assess the relative contribution of each type of effector mechanism to the overall effect. Much of our knowledge is gained by extrapolation from cell culture data to the in vivo situation. Another source of information comes from the use of animal models, mostly animals lacking one or the other type of effector cells [125]. However, it is often difficult to extrapolate from mice to humans, because these different classes of effector cells have a strikingly different functional specialization in both species. Human NK-cells are abundant, are present in a pre-activated state, and require no additional treatment before they can function as effectors for ab-mediated tumor cell lysis. By contrast, murine NK-cells are far less abundant; they are not pre-activated in their normal state in circulation. Moreover in mice, the function that is played in

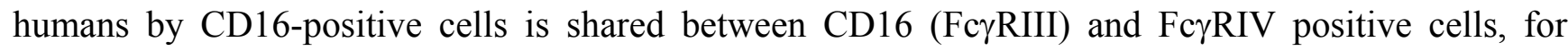
which there is no human equivalent [126]. Murine CD16-positive cells cannot be directly recruited for an effective ab-mediated tumor cell lysis, but require a prior activation, for example by treatment of the mice with poly I:C, in order to up regulate CD16 on the NK-cell surface and to empower them for ADCC [127,128]. For these reasons, we still have only limited knowledge about the spectrum of in vivo responses in human patients to a given therapeutic anti-tumor ab, and this spectrum probably also shows individual differences for each particular ab.

Inspite of this complexity, some common underlying features have emerged. One of these is that in humans CD16-positive effector cells, mostly NK-cells, macrophages, monocytes, $\gamma \delta$ T cells, plus some appropriately stimulated DCs, play a dominant role in the complex mixture of in vivo reactions to therapeutic abs with current clinical success in tumor treatment, such as rituximab, trastuzumab and cetuximab. This conclusion comes from initial observations that the therapeutic outcome of treatment of lymphoma patients with rituximab depended on their genetic makeup in CD16 alleles [129,130]. Two major allotypes of human CD16a are known, one carrying Valine at position 158 (158V), the other Phenylalanine (158F). The 158V allotype binds the Fc region of human IgG1 with higher affinity than the $158 \mathrm{~F}$ allotype. Cartron and colleagues genotyped the CD16a locus in lymphoma patients, which had not been previously treated with other therapies, and which had received a frontline treatment with rituximab [129]. The objective response rates 12 months after the start of therapy were $90 \%$ for the V/V and 51\% for the F/V patients. Similar findings were reported by Weng and Levy for patients with follicular lymphoma (FL), treated with Rituximab [130]. The V/V homozygous patients responded far better than the $\mathrm{F} / \mathrm{F}$ homozygous and the $\mathrm{V} / \mathrm{F}$ heterozygous patients. Therefore, in both studies, treatment outcome was more favorable for the $\mathrm{V} / \mathrm{V}$ homozygous patients than for carriers of the $\mathrm{F}$ allele, in line with the known stronger binding of the $\mathrm{V}$ allotype to the Fc portion of human IgG1. In conclusion, CD16a was of major importance for the treatment success of follicular lymphoma patients with rituximab. The authors of these studies further interpreted the data to imply, that ADCC, mediated by NK-cells, probably was the most important reaction in vivo for the success of this treatment, although strictly speaking, the data do not directly support this conclusion. On the basis of these data, it is not possible to distinguish unambiguously between the alternatives that the relevant CD16a-positive cells were NK-cells, macrophages, monocytes, $\gamma \delta$ T-cells, DCs or combinations of these. Most likely, the major CD16a-positive players in vivo were indeed the NK-cells, but the data only provide indirect rather than direct support for this conclusion. 
This finding was surprising, because one might have expected, that Fc $\gamma R$ I (CD64)-positive effectors might have played the predominant role, as this receptor binds with higher affinity to the Fc-portion of IgGs, and because neutrophilic granulocytes and monocytes are more numerous in the human circulation than NK-cells, macrophages, $\gamma \delta \mathrm{T}$ cells and CD16-positive DCs. However, this was not the result, and our interpretation is that CD64 on granulocytes, which is only induced after stimulation with certain cytokines, may not have been present on the granulocytes of these patients in sufficient surface density. These surprising results force us to conclude that the dominant variables determining the anti-tumor efficacy of an ab-derived agent are not simply the numerical abundance of the effector cells, nor the affinity of binding of a particular FcR to the therapeutic ab, but other more subtle parameters. Why CD16-positive effectors were more important for the action of rituximab in these patients than CD64-positive cells is still not entirely clear. Some possible, speculative reasons beyond the already mentioned regulated cell surface density of CD64 are, that maybe the CD16-positive cells were more readily available at the relevant location of the lymphoma cells, or that they were better suited to access and eliminate MRD and CSC cells in their niches than CD64-positive effectors, or that they formed more effective immunological synapses with the target cells mediated by the ab than CD64-positive effectors. Similar results have since been obtained for patients with different cancer types after treatment with trastuzumab and cetuximab [129-132]. The common conclusions are that CD16a-positive cells, most likely NK-cells, and the CD16a receptor played a dominant role for the treatment outcome of these cancers with the mentioned therapeutic abs, which carried an Fc-domain.

\subsubsection{NK-Cell Recruiting ab-Derivates}

Beyond complete Ig proteins, other molecular formats recruiting CD16-positive effectors have since been tested for their potential effectiveness as anti-cancer agents. Two different types of bispecific $\mathrm{ab}$-fragments were developed for the treatment of solid tumors. The first, a bispecific F(ab') $)_{2}$ targeting the EGFR and engaging CD16-positive effectors, mediated potent ADCC of EGFR-positive renal carcinoma cells in vitro [133]. The second, a bispecific ab targeting HER2/neu, which is over expressed on a subset of breast and other carcinomas, and engaging CD16, effectively lysed antigenpositive cancer cell lines in ADCC tests in vitro [36]. Two other HER2/neu-specific molecules engaging CD16-bearing effectors, a quadroma $a b$ and a recombinant trivalent bispecific $a b$, mediated a therapeutic effect in xenograft mouse models. The first one called 2B1 mediated potent lysis of SKOV-3 cells, a human ovarian carcinoma cell line used as a xenograft. A cellular therapy with human peripheral blood lymphocytes or lymphokine-activated killer cells and IL-2 alone, had only minimal effects on the xenograft growth, but the therapeutic effect was improved by a combination treatment with these cells plus $2 \mathrm{~B} 1[134,135]$. The second one, the trivalent bispecific ab, possesses three antigen binding moieties, two scFvs targeting HER2/neu and a Fab fragment engaging NK-cells (Figure 3E). The recombinant molecule induced more effective ADCC of SKBR3 cells than of MCF-7 cells; both cell lines are HER2/neu-positive cancer cells with different surface densities of the target molecules. The observation that the SKBR3 cells with a higher density of HER2/neu than the MCF-7 cells were eliminated more efficiently, indicates that lysis of the target cells was controlled by the cell surface density of HER2/neu. In animals xenografted with SK-OV-3 cells, the agent was more potent than an 
anti-HER2/neu scFv-Fc fusion protein (also called a mini-ab; Figure 3H), indicating, that direct recruiting of effector cells was more efficient than recruiting via the Fc-domain [136].

Figure 3. Schematic structure of NK-cell recruiting agents. (A) tandem bispecific single chain Fragment variable (bsscFv); (B) single chain triplebody (sctb); (C) two-chain diabody; (D) tandem diabody (TandAb); (E) bispecific Tribody (bsTb); (F) bispecific Bibody (bsBb); (G) dual-affinity re-targeting molecule (DART); (H) mini-ab; (I) immunoligand;

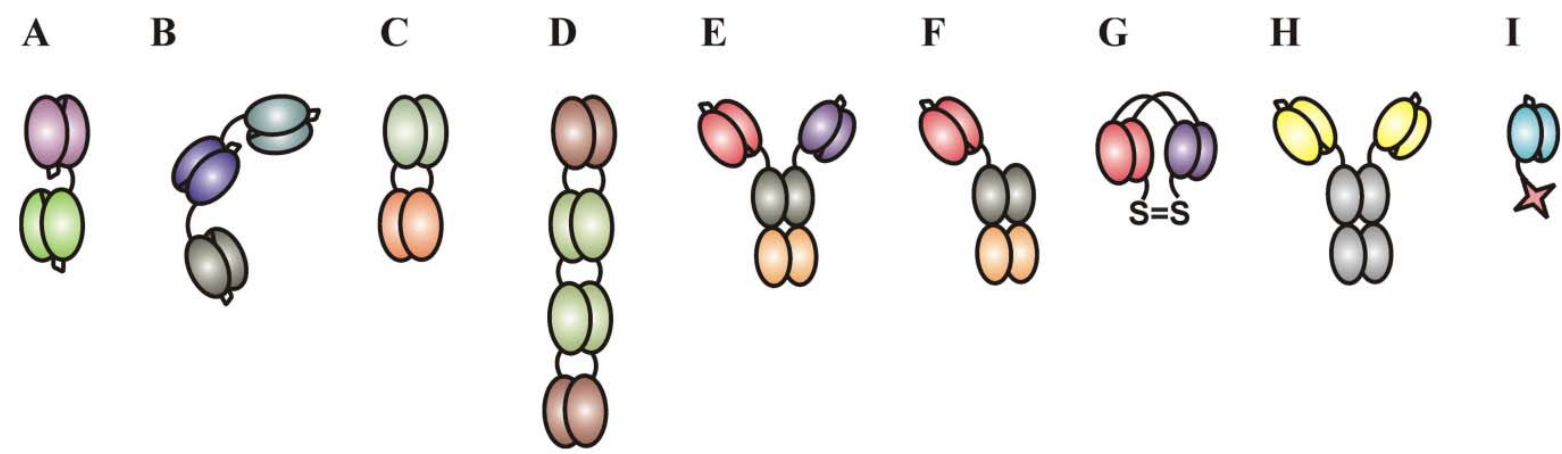

Several groups of investigators focused on the treatment of hematological malignancies and produced CD16-engaging bsscFvs, single chain triplebodies (sctbs), diabodies, tandem diabodies (TandAbs), bispecific tribodies (bsTbs), and dual-affinity retargeting (DART) molecules for use against these diseases (Figure $3 \mathrm{~A}-\mathrm{G}$ ). Our own team initially worked with recombinant scFvderivatives targeting either HLA class II or CD19 on B-lymphoid malignant cells and engaging CD16positive effectors. These were the bsscFvs HLAII-16 and 19-16 (Figure 3A) and the sctb 19-16-19 (Figure 3B) $[58,78,137]$. All three fusion proteins mediated potent lysis of tumor cell lines and primary cells from leukemia patients, using mononuclear cells (MNCs) from unrelated healthy donors, a subset of peripheral blood leukocytes comprising the NK-cell compartment, as effector cells. The MNC compartment contains several subsets of CD16-positive cells, and therefore, we attempted to further define, which subset contained the relevant effectors for this result. To this effect, the MNCs were fractionated using immuno-magnetic beads, and the subfractions were separately tested in ADCC reactions. Only the CD56-positive and CD16-positive NK-cell fractions, which were contained in the CD56-negative compartment, but not the CD56-negative NKT cells mediated ADCC with these agents. Two additional fusion proteins, a bsscFv and a sctb specific for CD33 and CD16, called 33-16 and 33-16-33, were used for similar ADCC experiments with immuno-magnetically fractionated subsets of effector cells (Figure 4) [138]. In these experiments the main cytotoxic effect was again mediated by CD16-bearing NK-cells and only a small percentage of the observed ADCC effect was mediated by other CD16-positive effector cells.

To take full advantage of the possibilities offered by the sctb format, dual-targeting sctbs with specificities for two different antigens on the same tumor cell were constructed $[59,139,140]$. These fusion proteins mediated efficient ADCC lysis of antigen-positive tumor-derived cell lines and primary tumor cells. The unique new capability of these agents, permitted by dual targeting of two different antigens on the same tumor cell, was a selectivity of ADCC lysis for antigen double-positive cells in the presence of equal numbers of antigen single-positive cells, mediated by NK-cells $[59,139,140]$. This is an exciting new result, because it opens the perspective that it may be possible in the future to 
find a pair of target antigens, which is present on tumor cells in higher combined density than on corresponding healthy cells, and which may therefore allow a preferential elimination of the cancer cells over the corresponding healthy cells, mediated by effector cells. Such a preferential elimination is a major objective of cancer therapy, which so far has not been fully reached by chemotherapeutic agents. It may even become possible in the future to define a pair of two antigens, which are present on CSCs in greater combined density than on the bulk of the tumor cells and on the corresponding normal tissue stem cells, and which may therefore permit a preferential elimination of CSCs and MRD-causing cells by such dual-targeting agents. This may allow us to achieve a longer lasting therapeutic effect $[141,142]$.

Figure 4. The bsscFv 33-16 (horizontal stripes) and the sctb 33-16-33 (vertical stripes) induced lysis of CD33-positive Molm-13 cells in an ADCC experiment with MNCs as effector cells at an E:T ratio of 10:1. The extent of lysis was raised when purified natural killer (NK) cells were used as effectors at the same E:T ratio. Enrichment of CD56-positive cells from the MNC portion also elevated the extent of lysis compared with the whole MNC population. Depletion of CD3 positive cells marginally reduced lysis, whereas after depletion of CD56-positive cells, lysis was strongly reduced, indicating that NKT-cells residing in this residual compartment, were not major contributors to the overall degree of lysis mediated by the sum of all CD16-positive effector cells. No lysis was obtained without effector cells. Open bars, control bsscFv 7-16; filled bars, control sctb 7-16-7, carrying scFv binding domains for CD7; checkered pattern, no ab-derivative added. ++, enriched for; --, depleted of; Data points are presented as mean values from triplicate determinations, error bars represent SEM; E:T ratio, effector-to-target cell ratio; MNC, mononuclear cells. From Singer 2010 [138] with permission.

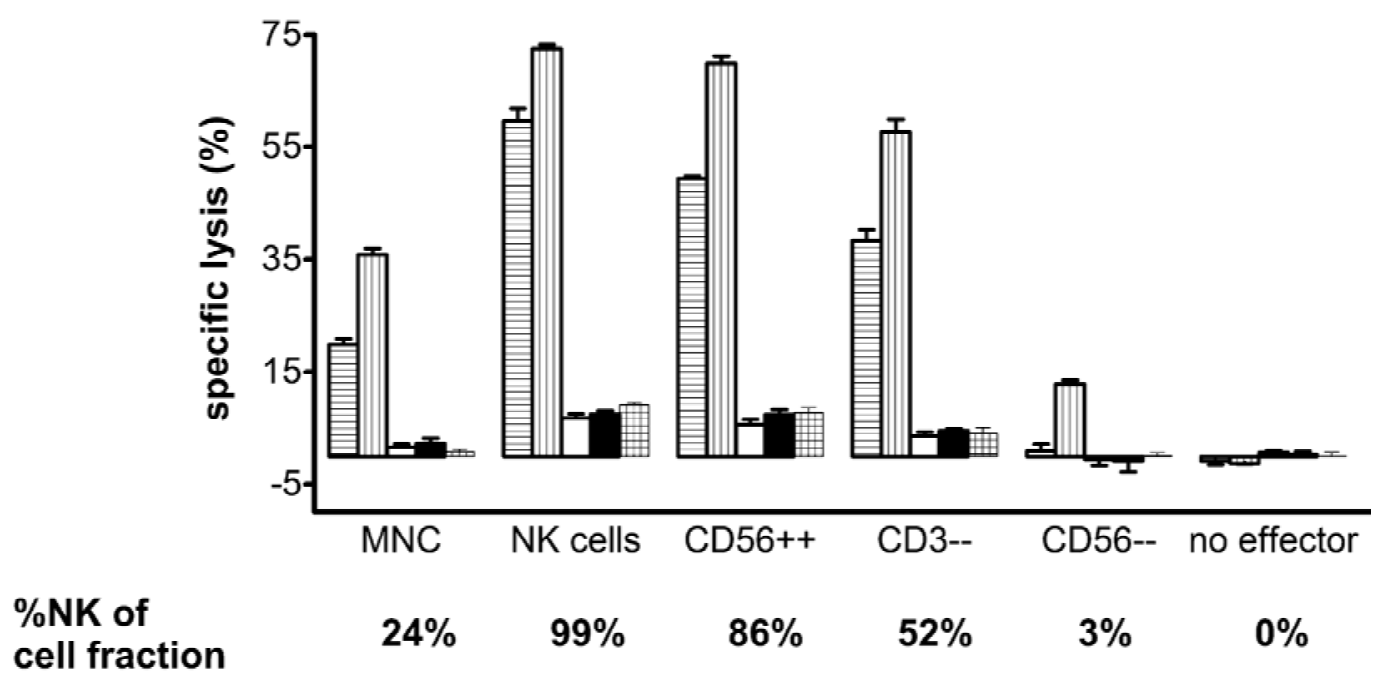

A bsTb (Figure 3E) with two binding sites for CD19 and one for CD16 showed overall superior properties in comparison to a bispecific bibody (bsBb) with only one binding site each for CD19 and CD16 (Figure 3F). The bsTb had a 3-fold higher avidity and mediated similar lysis of antigen positive cells at 6 -fold lower concentrations than the bsBb [143]. The addition of a second binding site for an antigen on the same tumor cell allowed investigators to reach the objective outlined above. It endows 
this molecular format with the desired inbuilt initial binding to the tumor cell. This design doubles the probability, that the agent will bind the tumor cell first, rather than the effector cell, and thereby makes it possible, that the effector cell can save its precious cargo until it has successfully engaged the tumor cell, and does not degranulate before this engagement is sealed. Moreover, this format of bsTbs also allows the design of dual-targeting agents, as discussed above for the sctb format. Inspite of these advantages of the sctb and bsTb formats, some issues regarding their stability and economic manufacturing remain to be addressed [141]. To approach these issues from a different angle, the format of DART molecules was created (Figure 3G). A DART protein targeting the Fc $\gamma$ RIIb and FcyRIII was produced with high production yields. It showed extended storage and serum stability and displayed very potent, dose-dependent cytotoxicity in retargeting human MNCs against B-lymphoma cell lines. Furthermore, this molecule was also able to mediate potent in vivo protective activity in a mouse model with xenografted human lymphoma cells [144].

Little and co-workers constructed a recombinant bispecific tetravalent tandem diabody (tandab; Figure 3D), generating two Fv binding domains each for CD16a and CD30, but composed of VL and VH components carried on different chains. This two-chain fusion protein (AFM13) inhibited tumor growth in a xenotransplanted Hodgkin lymphoma model in mice [145]. To increase the therapeutic effect mediated by diabodies (Figure 3C), a combination of two diabodies directed against CD19, which retargeted NK-cells and T-cells via CD16 and CD3, respectively, was tested in a mouse model. The combination of both diabodies produced a synergistic effect in vivo compared with the control groups, which were treated with only one of these agents [146]. After having obtained this synergistic effect, the authors tested different combinations of diabodies and other drugs. As a result, a monotherapy with thalidomide (an angiogenesis inhibitor) or with a CD19-CD16 specific diabody caused only a 50\% reduction in tumor growth rate in a subcutaneous tumor model, whereas the combination produced a synergistic effect resulting in a $74 \%$ reduction in mean tumor size [147].

The agents just mentioned above, which engage CD16-bearing effector cells, showed attractive results in preclinical studies, but only two of them have been advanced so far into clinical trials, where one produced promising initial results. AFM13 is currently evaluated in a clinical phase I study. This tetravalent tandem diabody with two scFv binding sites each for CD30 and CD16a (Figure 3D) so far was safe, well tolerated and showed clear signs of anti-tumor activity in patients with Hodgkin lymphoma (NCT01221571). These are very encouraging results, because they establish a precedent. They demonstrate that not only conventional, chemically linked bispecific whole abs, quadroma abs or chemically linked $\mathrm{F}(\mathrm{ab})_{2}$ fragments can be clinically active as shown by other authors two decades ago, but also recombinant bispecific agents, lacking an Fc domain, which engage CD16a-bearing effectors. This is major progress, because the conventional agents, although effective in clinical trials, have not been further pursued in their clinical development, due to manufacturing problems. The recombinant new formats will likely overcome these problems. They set the stage for a new class of agents, for which success is expected, because they rely on similar effector mechanisms as clinically successful abs, such as rituximab, trastuzumab and cetuximab, which also largely work, beside signaling-effects, through the engagement of CD16-bearing effectors in vivo [129,130]. These new agents can likely be administered in far lower doses, due to the absence of Fc-domains, and therefore signify progress for the patient, because they will likely be tolerated better with fewer side effects, and will be more affordable. 


\subsubsection{Immunoligands for the Recruitment of NK-Cells}

Many ab-derived agents engaging Fc $\gamma$ RIII will also bind the inhibitory GPI-linked variant CD16b expressed on neutrophilic granulocytes, as long as they do not bind an allele-specific CD16a epitope, which is not shared with CD16b. Binding to CD16b reduces the available plasma concentrations of such agents, due to absorption by the numerous neutrophilic granulocytes, and thus their therapeutic efficacy. To avoid this effect, the tandem diabody AFM 13 described above uses a binding site with specificity for a private epitope on CD16a. In a different approach, a series of new recombinant proteins were designed to engage NK-cells through the activating receptor NKG2D, which is not shared with other leukocytes outside the NK-compartment. This receptor binds a number of different ligands, and therefore, fusion proteins between $\mathrm{scFv}$ components targeting tumor cells and these ligands, which are designed for the engagement of NK-cells, offer an attractive alternative. The bestcharacterized NKG2D ligands to date are the MHC class-I-chain-related proteins A and B (MICA, MICB), and two glycoproteins, binding to the human cytomegalovirus (HCMV) UL16 protein, called UL16-binding proteins 1 and 2 (ULBP1; ULBP2). These ligands bind to and activate human NK-cells [148]. A number of fusion proteins with NKG2D ligands have been produced and tested in view of potential therapeutic applications (Figure 3I). In some of these agents, recombinant MICA was chemically conjugated to $\mathrm{F}(\mathrm{ab}$ ')s specific for tumor-associated antigens such as CEA, HER2/neu and CD20. These molecules mediated lysis of antigen-positive tumor cells by engaging NK-cells. The effects were blocked by pre-incubation of the effector cells with an NKG2D-specific ab [149].

Another novel recombinant fusion protein, ULBP-BB4, carrying ULBP2 as the ligand for NKG2D fused to an $\mathrm{scFv}$ domain specific for CD138 was tested. CD138 (syndecan-1) is expressed on pre-B cells, immature B-cells and plasma cells, but not on mature circulating B-cells. It is also expressed on a variety of tumor cells, including malignant cells from multiple myeloma patients [150] and is a potentially interesting target for immune-therapeutic approaches against multiple myeloma [151]. In one particular series of experiments, mice were xenografted with subcutaneously growing CD138positive tumor cells, and then the fusion protein ULBP-BB4 was administered together with a dose of adoptively transferred human MNCs. The treatment effectively inhibited tumor growth, most likely due to in vivo ADCC effects mediated by the NK-cells contained in the transferred MNCs [152]. In a similar set of experiments, Cho and colleagues produced a fusion protein between the NKG2D ligand Rae-1 $\beta$ and an IgG3 ab specific for HER2/neu. In a mouse model with xenografted human breast cancer cells this fusion protein mediated enhanced innate and adaptive anti-tumor immune responses, including an augmented response of murine cytotoxic NK-cells. A depletion of the murine NK- or CD8-positive T-cells resulted in an inhibition of the anti-tumor effect of the agent. This result indicated essential roles for the NK- and T-cells in the observed anti-tumor activity. Surviving mice, which were re-challenged with tumor cells after treatment with this anti-HER2/neu-Rae-1 $\beta$ fusion protein, showed decreased tumor growth, indicating the development of an adaptive memory response [153].

Using the same design principle, an immunoligand fusing an scFv targeting the prostate-specific membrane antigen PSMA with the NKG2D ligand ULBP2 was produced for the treatment of prostate cancer. Shortening of the linker between the variable heavy and light chains of the scFv led to the formation of oligomers. The oligomeric proteins enhanced NK-cell activity and mediated the highest cytotoxicity against the tumor cells. The efficacy of the oligomeric agents was confirmed in a prostate 
cancer xenograft model in mice, and a strong activity against established tumors was obtained [154]. Finally, in a study performed by Kellner and colleagues, two bifunctional recombinant molecules consisting of MICA and ULBP2, respectively, as the NKG2D ligand and an scFv targeting CD20, were generated. Both proteins mediated significant ADCC lysis of CD20 positive cell lines and of CD20 positive tumor cell samples from patients with chronic lymphocytic leukemia (CLL), marginal zone lymphoma (MZL), or mantle cell lymphoma (MCL), mediated by NK-cells. Increased expression levels of CD20 led to an increased susceptibility of the target cells for ADCC lysis mediated by the recombinant proteins. Remarkably, the immunoligand containing ULBP2 triggered stronger ADCC in than the protein carrying MICA as the NKG2D ligand, pointing to potentially different mechanisms of signal transduction from the same cell surface receptor into the NK-cells [155].

Taken together, these data suggest, that NK cells can be engaged with advantage by a variety of different recombinant fusion proteins addressing different activatory receptors on their surface for the targeted elimination of human tumor cells, both in vitro and in vivo. They are further attractive, because their numbers can be expanded significantly ex vivo and the expanded cells remain highly active for ADCC after recruitment through CD16-engaging abs and ab-derived agents [156-158]. In our team, we have been able to expand the number of NK-cells from peripheral blood of healthy donors and from cryo-preserved leukapheresis samples by several hundred-fold through culture for 21 days in the presence of IL-2 [159]. Such ex vivo expanded NK cells are suited as cellular therapeutics for adoptive transfer in the context of cancer treatment, provided they are produced under the usual stringent requirements for cellular therapeutics [160].

\section{Conclusions}

Targeted therapy with ab-derived agents engaging select subsets of effector cells of the human defense system for the elimination of cancer cells, offers great promise. Clinical results with catumaxomab and BiTE molecules retargeting $\mathrm{T}$ cells have already demonstrated the therapeutic potential of T-cells as effectors. NK-cells are also suitable effectors for cancer therapy with ab-derived agents, due to their ability to mediate ADCC and the possibility of their ex vivo expansion followed by adoptive transfer. An ongoing phase I study with the first NK-cell recruiting bispecific agent, AFM13, produced promising initial results. It is therefore probably only a question of time until NK-cells recruited by ab-derived agents will also become an established component of cancer therapy. Both cell types have their particular advantages, and a combination of NK- and T-cell recruiting agents may become an even more powerful option. Next on the horizon is the development of ab-derived agents engaging tumor infiltrating macrophages and granulocytes as effectors. The central idea is that this effector-cell engaging approach may be gentler and may be better tolerated by patients than approaches employing ADCs. The effector-cell engaging approach builds on the natural defense mechanisms that are already used by the normal immune-surveillance against spontaneously arising cancers of non-viral etiology. Antibodies already successful in cancer therapy to date, such as rituximab, also rely on effector cells, and therefore it appears promising to engage and amplify these same mechanisms which are already of proven efficacy in the normal functioning of the human organism and therefore should be particularly gentle and well tolerated. 


\section{Acknowledgments}

The authors thank Domenica Saul, Stefanie Nowecki and Barbara Bock for technical assistance, Drs. Andreas Mackensen, Bernhard Stockmeyer and Fuat Oduncu for providing primary cells from AML patients and valuable clinical information, and Ms. Donata Wehr and Brigitte Woelfel for administrative assistance. This research was supported by grants from the DFG (Deutsche Forschungsgesellschaft) to G.H.F. (SFB 643 project 6) and A.M. (SFB 643 project 8), a research grant No. 2007.049. from the Wilhelm Sander Foundation, Neustadt, Germany to G.H.F and B.S., and support from the Stiftung Deutsche Krebshilfe (project No. 08 42) as well as the Association 'Kaminkehrer helfen krebskranken Kindern' (Chimney Sweeps support children with cancer) to G.H.F.

\section{References and Notes}

1. Rahlff, J.; Trusch, M.; Haag, F.; Bacher, U.; Horst, A.; Schluter, H.; Binder, M. Antigenspecificity of oligoclonal abnormal protein bands in multiple myeloma after allogeneic stem cell transplantation. Cancer Immunol. Immunother. 2012, doi:10.1007/s00262-012-1220-x.

2. Sahin, U.; Tureci, O.; Schmitt, H.; Cochlovius, B.; Johannes, T.; Schmits, R.; Stenner, F.; Luo, G.; Schobert, I.; Pfreundschuh, M. Human neoplasms elicit multiple specific immune responses in the autologous host. Proc. Natl. Acad. Sci. USA 1995, 92, 11810-11813.

3. Scanlan, M.J.; Chen, Y.T.; Williamson, B.; Gure, A.O.; Stockert, E.; Gordan, J.D.; Tureci, O.; Sahin, U.; Pfreundschuh, M.; Old, L.J. Characterization of human colon cancer antigens recognized by autologous antibodies. Int. J. Cancer 1998, 76, 652-658.

4. Fridman, W.H.; Pages, F.; Sautes-Fridman, C.; Galon, J. The immune contexture in human tumours: Impact on clinical outcome. Nat. Rev. Cancer 2012, 12, 298-306.

5. Hanahan, D.; Weinberg, R.A. Hallmarks of cancer: The next generation. Cell 2011, 144, 646-674.

6. Alley, S.C.; Okeley, N.M.; Senter, P.D. Antibody-drug conjugates: Targeted drug delivery for cancer. Curr. Opin. Chem. Biol. 2011, 14, 529-537.

7. Carter, P. Improving the efficacy of antibody-based cancer therapies. Nat. Rev. Cancer 2001, 1, 118-129.

8. Dalken, B.; Giesubel, U.; Knauer, S.K.; Wels, W.S. Targeted induction of apoptosis by chimeric granzyme B fusion proteins carrying antibody and growth factor domains for cell recognition. Cell Death Differ. 2006, 13, 576-585.

9. Kovtun, Y.V.; Audette, C.A.; Ye, Y.; Xie, H.; Ruberti, M.F.; Phinney, S.J.; Leece, B.A.; Chittenden, T.; Blattler, W.A.; Goldmacher, V.S. Antibody-drug conjugates designed to eradicate tumors with homogeneous and heterogeneous expression of the target antigen. Cancer Res. 2006, 66, 3214-3221.

10. Sievers, E.L.; Appelbaum, F.R.; Spielberger, R.T.; Forman, S.J.; Flowers, D.; Smith, F.O.; Shannon-Dorcy, K.; Berger, M.S.; Bernstein, I.D. Selective ablation of acute myeloid leukemia using antibody-targeted chemotherapy: A phase I study of an anti-CD33 calicheamicin immunoconjugate. Blood 1999, 93, 3678-3684.

11. Stasi, R. Gemtuzumab ozogamicin: An anti-CD33 immunoconjugate for the treatment of acute myeloid leukaemia. Expert Opin. Biol. Ther. 2008, 8, 527-540. 
12. Zwaan, C.M.; Reinhardt, D.; Zimmerman, M.; Hasle, H.; Stary, J.; Stark, B.; Dworzak, M.; Creutzig, U.; Kaspers, G.J. Salvage treatment for children with refractory first or second relapse of acute myeloid leukaemia with gemtuzumab ozogamicin: Results of a phase II study. $\mathrm{Br}$. $J$. Haematol. 2010, 148, 768-776.

13. Younes, A.; Yasothan, U.; Kirkpatrick, P. Brentuximab vedotin. Nat. Rev. Drug Discov. 2012, 11, 19-20.

14. Redner, R.L. Why doesn't imatinib cure chronic myeloid leukemia? Oncologist 2010, 15, 182-186.

15. Horton, H.M.; Bernett, M.J.; Pong, E.; Peipp, M.; Karki, S.; Chu, S.Y.; Richards, J.O.; Vostiar, I.; Joyce, P.F.; Repp, R.; et al. Potent in vitro and in vivo activity of an Fc-engineered anti-CD19 monoclonal antibody against lymphoma and leukemia. Cancer Res. 2008, 68, 8049-8057.

16. Ferrara, C.; Grau, S.; Jager, C.; Sondermann, P.; Brunker, P.; Waldhauer, I.; Hennig, M.; Ruf, A.; Rufer, A.C.; Stihle, M.; et al. Unique carbohydrate-carbohydrate interactions are required for high affinity binding between FcgammaRIII and antibodies lacking core fucose. Proc. Natl. Acad. Sci. USA 2011, 108, 12669-12674.

17. Shinkawa, T.; Nakamura, K.; Yamane, N.; Shoji-Hosaka, E.; Kanda, Y.; Sakurada, M.; Uchida, K.; Anazawa, H.; Satoh, M.; Yamasaki, M.; et al. The absence of fucose but not the presence of galactose or bisecting $\mathrm{N}$-acetylglucosamine of human IgG1 complex-type oligosaccharides shows the critical role of enhancing antibody-dependent cellular cytotoxicity. J. Biol. Chem. 2003, 278, 3466-3473.

18. Vidal, L.; Gafter-Gvili, A.; Salles, G.; Dreyling, M.H.; Ghielmini, M.; Hsu Schmitz, S.F.; Pettengell, R.; Witzens-Harig, M.; Shpilberg, O. Rituximab maintenance for the treatment of patients with follicular lymphoma: An updated systematic review and meta-analysis of randomized trials. J. Natl. Cancer Inst. 2011, 103, 1799-1806.

19. Preithner, S.; Elm, S.; Lippold, S.; Locher, M.; Wolf, A.; da Silva, A.J.; Baeuerle, P.A.; Prang, N.S. High concentrations of therapeutic IgG1 antibodies are needed to compensate for inhibition of antibody-dependent cellular cytotoxicity by excess endogenous immunoglobulin G. Mol. Immunol. 2006, 43, 1183-1193.

20. Lopez-Guillermo, A.; Mercadal, S. The clinical use of antibodies in haematological malignancies. Ann. Oncol. 2007, 18 (Suppl. 9), ix51-ix57.

21. Indik, Z.K.; Park, J.G.; Hunter, S.; Schreiber, A.D. The molecular dissection of Fc gamma receptor mediated phagocytosis. Blood 1995, 86, 4389-4399.

22. Boruchov, A.M.; Heller, G.; Veri, M.C.; Bonvini, E.; Ravetch, J.V.; Young, J.W. Activating and inhibitory IgG Fc receptors on human DCs mediate opposing functions. J. Clin. Invest. 2005, 115, 2914-2923.

23. Nimmerjahn, F.; Ravetch, J.V. Antibodies, Fc receptors and cancer. Curr. Opin. Immunol. 2007, 19, 239-245.

24. Selvaraj, P.; Fifadara, N.; Nagarajan, S.; Cimino, A.; Wang, G. Functional regulation of human neutrophil Fc gamma receptors. Immunol. Res. 2004, 29, 219-230.

25. Xiang, Z.; Cutler, A.J.; Brownlie, R.J.; Fairfax, K.; Lawlor, K.E.; Severinson, E.; Walker, E.U.; Manz, R.A.; Tarlinton, D.M.; Smith, K.G. FcgammaRIIb controls bone marrow plasma cell persistence and apoptosis. Nat. Immunol. 2007, 8, 419-429. 
26. Nimmerjahn, F.; Ravetch, J.V. Fcgamma receptors: Old friends and new family members. Immunity 2006, 24, 19-28.

27. Fanger, M.W.; Segal, D.M.; Romet-Lemonne, J.L. Bispecific antibodies and targeted cellular cytotoxicity. Immunol. Today 1991, 12, 51-54.

28. Keler, T.; Graziano, R.F.; Mandal, A.; Wallace, P.K.; Fisher, J.; Guyre, P.M.; Fanger, M.W.; Deo, Y.M. Bispecific antibody-dependent cellular cytotoxicity of HER2/neu-overexpressing tumor cells by Fc gamma receptor type I-expressing effector cells. Cancer Res. 1997, 57, 4008-4014.

29. Muller, D.; Kontermann, R.E. Recombinant bispecific antibodies for cellular cancer immunotherapy. Curr. Opin. Mol. Ther. 2007, 9, 319-326.

30. Ochiai, K.; Wang, B.; Rieger, A.; Kilgus, O.; Maurer, D.; Fodinger, D.; Kinet, J.P.; Sting1, G.; Tomioka, H. A review on Fc epsilon RI on human epidermal Langerhans cells. Int. Arch. Allergy Immunol. 1994, 104 (Suppl. 1), 63-64.

31. Prussin, C.; Metcalfe, D.D. 5. IgE, mast cells, basophils, and eosinophils. J. Allergy Clin. Immunol. 2006, 117, (Suppl. 2 Mini-Primer), S450-S456.

32. von Bubnoff, D.; Novak, N.; Kraft, S.; Bieber, T. The central role of FcepsilonRI in allergy. Clin. Exp. Dermatol. 2003, 28, 184-187.

33. Kikutani, H.; Yokota, A.; Uchibayashi, N.; Yukawa, K.; Tanaka, T.; Sugiyama, K.; Barsumian, E.L.; Suemura, M.; Kishimoto, T. Structure and function of Fc epsilon receptor II (Fc epsilon RII/CD23): A point of contact between the effector phase of allergy and B cell differentiation. Ciba Found. Symp. 1989, 147, 23-31; discussion 31-35.

34. Hamre, R.; Farstad, I.N.; Brandtzaeg, P.; Morton, H.C. Expression and modulation of the human immunoglobulin A Fc receptor (CD89) and the FcR gamma chain on myeloid cells in blood and tissue. Scand. J. Immunol. 2003, 57, 506-516.

35. Stockmeyer, B.; Dechant, M.; van Egmond, M.; Tutt, A.L.; Sundarapandiyan, K.; Graziano, R.F.; Repp, R.; Kalden, J.R.; Gramatzki, M.; Glennie, M.J.; et al. Triggering Fc alpha-receptor I (CD89) recruits neutrophils as effector cells for CD20-directed antibody therapy. J. Immunol. 2000, 165, 5954-5961.

36. Stockmeyer, B.; Valerius, T.; Repp, R.; Heijnen, I.A.; Buhring, H.J.; Deo, Y.M.; Kalden, J.R.; Gramatzki, M.; van de Winkel, J.G. Preclinical studies with Fc(gamma)R bispecific antibodies and granulocyte colony-stimulating factor-primed neutrophils as effector cells against HER-2/neu overexpressing breast cancer. Cancer Res. 1997, 57, 696-701.

37. Honeychurch, J.; Tutt, A.L.; Valerius, T.; Heijnen, I.A.; Van De Winkel, J.G.; Glennie, M.J. Therapeutic efficacy of FcgammaRI/CD64-directed bispecific antibodies in B-cell lymphoma. Blood 2000, 96, 3544-3552.

38. Ranft, K.; Thepen, T.; Fischer, R.; Barth, S.; Stocker, M. Recombinant bispecific single chain antibody fragments induce Fc gamma-receptor-mediated elimination of CD30+ lymphoma cells. Cancer Lett. 2009, 282, 187-194.

39. Sundarapandiyan, K.; Keler, T.; Behnke, D.; Engert, A.; Barth, S.; Matthey, B.; Deo, Y.M.; Graziano, R.F. Bispecific antibody-mediated destruction of Hodgkin's lymphoma cells. J. Immunol. Methods 2001, 248, 113-123. 
40. Ely, P.; Wallace, P.K.; Givan, A.L.; Graziano, R.F.; Guyre, P.M.; Fanger, M.W. Bispecificarmed, interferon gamma-primed macrophage-mediated phagocytosis of malignant non-Hodgkin's lymphoma. Blood 1996, 87, 3813-3821.

41. Borchmann, P.; Schnell, R.; Fuss, I.; Manzke, O.; Davis, T.; Lewis, L.D.; Behnke, D.; Wickenhauser, C.; Schiller, P.; Diehl, V.; et al. Phase 1 trial of the novel bispecific molecule $\mathrm{H} 22 \mathrm{xKi}-4$ in patients with refractory Hodgkin lymphoma. Blood 2002, 100, 3101-3107.

42. Fury, M.G.; Lipton, A.; Smith, K.M.; Winston, C.B.; Pfister, D.G. A phase-I trial of the epidermal growth factor receptor directed bispecific antibody MDX-447 without and with recombinant human granulocyte-colony stimulating factor in patients with advanced solid tumors. Cancer Immunol. Immunother. 2008, 57, 155-163.

43. Posey, J.A.; Raspet, R.; Verma, U.; Deo, Y.M.; Keller, T.; Marshall, J.L.; Hodgson, J.; Mazumder, A.; Hawkins, M.J. A pilot trial of GM-CSF and MDX-H210 in patients with erbB-2positive advanced malignancies. J. Immunother. 1999, 22, 371-379.

44. James, N.D.; Atherton, P.J.; Jones, J.; Howie, A.J.; Tchekmedyian, S.; Curnow, R.T. A phase II study of the bispecific antibody MDX-H210 (anti-HER2 x CD64) with GM-CSF in HER2+ advanced prostate cancer. Br. J. Cancer 2001, 85, 152-156.

45. Guettinger, Y.; Barbin, K.; Peipp, M.; Bruenke, J.; Dechant, M.; Horner, H.; Thierschmidt, D.; Valerius, T.; Repp, R.; Fey, G.H.; Stockmeyer, B. A recombinant bispecific single-chain fragment variable specific for HLA class II and Fc alpha RI (CD89) recruits polymorphonuclear neutrophils for efficient lysis of malignant B lymphoid cells. J. Immunol. 2010, 184, 1210-1217.

46. Stadick, H.; Stockmeyer, B.; Kuhn, R.; Schrott, K.M.; Kalden, J.R.; Glennie, M.J.; van de Winkel, J.G.; Gramatzki, M.; Valerius, T.; Elsasser, D. Epidermal growth factor receptor and g250: Useful target antigens for antibody mediated cellular cytotoxicity against renal cell carcinoma? J. Urol. 2002, 167, 707-712.

47. Valerius, T.; Stockmeyer, B.; van Spriel, A.B.; Graziano, R.F.; van den Herik-Oudijk, I.E.; Repp, R.; Deo, Y.M.; Lund, J.; Kalden, J.R.; Gramatzki, M.; et al. FcalphaRI (CD89) as a novel trigger molecule for bispecific antibody therapy. Blood 1997, 90, 4485-4492.

48. van Egmond, M.; Hanneke van Vuuren, A.J.; van de Winkel, J.G. The human Fe receptor for IgA (Fc alpha RI, CD89) on transgenic peritoneal macrophages triggers phagocytosis and tumor cell lysis. Immunol. Lett. 1999, 68, 83-87.

49. van Egmond, M.; van Vuuren, A.J.; Morton, H.C.; van Spriel, A.B.; Shen, L.; Hofhuis, F.M.; Saito, T.; Mayadas, T.N.; Verbeek, J.S.; van de Winkel, J.G. Human immunoglobulin A receptor (FcalphaRI, CD89) function in transgenic mice requires both FcR gamma chain and CR3 (CD11b/CD18). Blood 1999, 93, 4387-4394.

50. Bonde, A.K.; Tischler, V.; Kumar, S.; Soltermann, A.; Schwendener, R.A. Intratumoral macrophages contribute to epithelial-mesenchymal transition in solid tumors. BMC Cancer 2012, 12,35 .

51. Maniecki, M.B.; Etzerodt, A.; Ulhoi, B.P.; Steiniche, T.; Borre, M.; Dyrskjot, L.; Orntoft, T.F.; Moestrup, S.K.; Moller, H.J. Tumor-promoting macrophages induce the expression of the macrophagespecific receptor CD163 in malignant cells. Int. J. Cancer 2012, doi:10.1002/ijc. 27506. 
52. Willingham, S.B.; Volkmer, J.P.; Gentles, A.J.; Sahoo, D.; Dalerba, P.; Mitra, S.S.; Wang, J.; Contreras-Trujillo, H.; Martin, R.; Cohen, J.D.; et al. The CD47-signal regulatory protein alpha (SIRPa) interaction is a therapeutic target for human solid tumors. Proc. Natl. Acad. Sci. USA 2012, 109, 6662-6667.

53. Chao, M.P.; Alizadeh, A.A.; Tang, C.; Jan, M.; Weissman-Tsukamoto, R.; Zhao, F.; Park, C.Y.; Weissman, I.L.; Majeti, R. Therapeutic antibody targeting of CD47 eliminates human acute lymphoblastic leukemia. Cancer Res. 2011, 71, 1374-1384.

54. Edris, B.; Weiskopf, K.; Volkmer, A.K.; Volkmer, J.P.; Willingham, S.B.; Contreras-Trujillo, H.; Liu, J.; Majeti, R.; West, R.B.; Fletcher, J.A.; et al. Antibody therapy targeting the CD47 protein is effective in a model of aggressive metastatic leiomyosarcoma. Proc. Natl. Acad. Sci. USA 2012, 109, 6656-6661.

55. Chao, M.P.; Jaiswal, S.; Weissman-Tsukamoto, R.; Alizadeh, A.A.; Gentles, A.J.; Volkmer, J.; Weiskopf, K.; Willingham, S.B.; Raveh, T.; Park, C.Y.; et al. Calreticulin is the dominant prophagocytic signal on multiple human cancers and is counterbalanced by CD47. Sci. Transl. Med. 2010, 2, 63ra94.

56. Gardai, S.J.; McPhillips, K.A.; Frasch, S.C.; Janssen, W.J.; Starefeldt, A.; Murphy-Ullrich, J.E.; Bratton, D.L.; Oldenborg, P.A.; Michalak, M.; Henson, P.M. Cell-surface calreticulin initiates clearance of viable or apoptotic cells through trans-activation of LRP on the phagocyte. Cell 2005, $123,321-334$.

57. Chao, M.P.; Weissman, I.L.; Majeti, R. The CD47-SIRPalpha pathway in cancer immune evasion and potential therapeutic implications. Curr. Opin. Immunol. 2012, 24, 225-232.

58. Kellner, C.; Bruenke, J.; Stieglmaier, J.; Schwemmlein, M.; Schwenkert, M.; Singer, H.; Mentz, K.; Peipp, M.; Lang, P.; Oduncu, F.; et al. A novel CD19-directed recombinant bispecific antibody derivative with enhanced immune effector functions for human leukemic cells. J. Immunother. 2008, 31, 871-884.

59. Kugler, M.; Stein, C.; Kellner, C.; Mentz, K.; Saul, D.; Schwenkert, M.; Schubert, I.; Singer, H.; Oduncu, F.; Stockmeyer, B.; et al. A recombinant trispecific single-chain Fv derivative directed against CD123 and CD33 mediates effective elimination of acute myeloid leukaemia cells by dual targeting. Br. J. Haematol. 2010, 150, 574-586.

60. Stevenson, F.K.; Stevenson, G.T. Follicular lymphoma and the immune system: From pathogenesis to antibody therapy. Blood 2012, 119, 3659-3667.

61. Linsley, P.S.; Brady, W.; Grosmaire, L.; Aruffo, A.; Damle, N.K.; Ledbetter, J.A. Binding of the $B$ cell activation antigen B7 to CD28 costimulates $T$ cell proliferation and interleukin 2 mRNA accumulation. J. Exp. Med. 1991, 173, 721-730.

62. Rudd, C.E.; Schneider, H. Unifying concepts in CD28, ICOS and CTLA4 co-receptor signalling. Nat. Rev. Immunol. 2003, 3, 544-556.

63. van der Merwe, P.A.; Bodian, D.L.; Daenke, S.; Linsley, P.; Davis, S.J. CD80 (B7-1) binds both CD28 and CTLA-4 with a low affinity and very fast kinetics. J. Exp. Med. 1997, 185, 393-403.

64. Hodi, F.S.; O'Day, S.J.; McDermott, D.F.; Weber, R.W.; Sosman, J.A.; Haanen, J.B.; Gonzalez, R.; Robert, C.; Schadendorf, D.; Hassel, J.C.; et al. Improved survival with ipilimumab in patients with metastatic melanoma. N. Engl. J. Med. 2010, 363, 711-723. 
65. Khong, H.T.; Wang, Q.J.; Rosenberg, S.A. Identification of multiple antigens recognized by tumor-infiltrating lymphocytes from a single patient: Tumor escape by antigen loss and loss of MHC expression. J. Immunother. 2004, 27, 184-190.

66. Cabrera, T.; Lara, E.; Romero, J.M.; Maleno, I.; Real, L.M.; Ruiz-Cabello, F.; Valero, P.; Camacho, F.M.; Garrido, F. HLA class I expression in metastatic melanoma correlates with tumor development during autologous vaccination. Cancer Immunol. Immunother. 2007, 56, 709-717.

67. Lanier, L.L. Follow the leader: NK cell receptors for classical and nonclassical MHC class I. Cell 1998, 92, 705-707.

68. Ferrucci, P.F.; Tosti, G.; di Pietro, A.; Passoni, C.; Pari, C.; Tedeschi, I.; Cataldo, F.; Martinoli, C.; Testori, A. Newly identified tumor antigens as promising cancer vaccine targets for malignant melanoma treatment. Curr. Top. Med. Chem. 2012, 12, 11-31.

69. Brahmer, J.R.; Drake, C.G.; Wollner, I.; Powderly, J.D.; Picus, J.; Sharfman, W.H.; Stankevich, E.; Pons, A.; Salay, T.M.; McMiller, T.L.; et al. Phase I study of single-agent anti-programmed death-1 (MDX-1106) in refractory solid tumors: Safety, clinical activity, pharmacodynamics, and immunologic correlates. J. Clin. Oncol. 2010, 28, 3167-3175.

70. Madrenas, J.; Chau, L.A.; Teft, W.A.; Wu, P.W.; Jussif, J.; Kasaian, M.; Carreno, B.M.; Ling, V. Conversion of CTLA-4 from inhibitor to activator of T cells with a bispecific tandem single-chain Fv ligand. J. Immunol. 2004, 172, 5948-5956.

71. Curran, M.A.; Kim, M.; Montalvo, W.; Al-Shamkhani, A.; Allison, J.P. Combination CTLA-4 blockade and 4-1BB activation enhances tumor rejection by increasing T-cell infiltration, proliferation, and cytokine production. PLoS One 2011, 6, e19499.

72. Curran, M.A.; Montalvo, W.; Yagita, H.; Allison, J.P. PD-1 and CTLA-4 combination blockade expands infiltrating $\mathrm{T}$ cells and reduces regulatory $\mathrm{T}$ and myeloid cells within B16 melanoma tumors. Proc. Natl. Acad. Sci. USA 2010, 107, 4275-4280.

73. Fisher, T.S.; Kamperschroer, C.; Oliphant, T.; Love, V.A.; Lira, P.D.; Doyonnas, R.; Bergqvist, S.; Baxi, S.M.; Rohner, A.; Shen, A.C.; et al. Targeting of 4-1BB by monoclonal antibody PF05082566 enhances T-cell function and promotes anti-tumor activity. Cancer Immunol. Immunother. 2012, doi:10.1007/s00262-012-1237-1.

74. Melero, I.; Shuford, W.W.; Newby, S.A.; Aruffo, A.; Ledbetter, J.A.; Hellstrom, K.E.; Mittler, R.S.; Chen, L. Monoclonal antibodies against the 4-1BB T-cell activation molecule eradicate established tumors. Nat. Med. 1997, 3, 682-685.

75. Attarwala, H. TGN1412: From discovery to disaster. J. Young Pharm. 2010, 2, 332-336.

76. Suntharalingam, G.; Perry, M.R.; Ward, S.; Brett, S.J.; Castello-Cortes, A.; Brunner, M.D.; Panoskaltsis, N. Cytokine storm in a phase 1 trial of the anti-CD28 monoclonal antibody TGN1412. N. Engl. J. Med. 2006, 355, 1018-1028.

77. Otz, T.; Grosse-Hovest, L.; Hofmann, M.; Rammensee, H.G.; Jung, G. A bispecific single-chain antibody that mediates target cell-restricted, supra-agonistic CD28 stimulation and killing of lymphoma cells. Leukemia 2009, 23, 71-77.

78. Bruenke, J.; Barbin, K.; Kunert, S.; Lang, P.; Pfeiffer, M.; Stieglmaier, K.; Niethammer, D.; Stockmeyer, B.; Peipp, M.; Repp, R.; et al. Effective lysis of lymphoma cells with a stabilised bispecific single-chain Fv antibody against CD19 and FcgammaRIII (CD16). Br. J. Haematol. 2005, 130, 218-228. 
79. Bryceson, Y.T.; Chiang, S.C.; Darmanin, S.; Fauriat, C.; Schlums, H.; Theorell, J.; Wood, S.M. Molecular mechanisms of natural killer cell activation. J. Innate Immun. 2011, 3, 216-226.

80. de Bruyn, M.; Bremer, E.; Helfrich, W. Antibody-based fusion proteins to target death receptors in cancer. Cancer Lett. 2011, doi:10.1016/j.canlet.2010.11.006.

81. de Bruyn, M.; Wei, Y.; Wiersma, V.R.; Samplonius, D.F.; Klip, H.G.; van der Zee, A.G.; Yang, B.; Helfrich, W.; Bremer, E. Cell surface delivery of TRAIL strongly augments the tumoricidal activity of T cells. Clin. Cancer Res. 2011, 17, 5626-5637.

82. Majeti, R.; Becker, M.W.; Tian, Q.; Lee, T.L.; Yan, X.; Liu, R.; Chiang, J.H.; Hood, L.; Clarke, M.F.; Weissman, I.L. Dysregulated gene expression networks in human acute myelogenous leukemia stem cells. Proc. Natl. Acad. Sci. USA 2009, 106, 3396-3401.

83. ten Cate, B.; de Bruyn, M.; Wei, Y.; Bremer, E.; Helfrich, W. Targeted elimination of leukemia stem cells; a new therapeutic approach in hemato-oncology. Curr. Drug Targets 2011, 11, 95-110.

84. Kontermann, R.E. Bispecific Antibodies: Developments and current perspectives. In Bispecific Antibodies, 1st ed.; Kontermann, R.E., Ed.; Springer-Verlag: Berlin, Germany, 2011; p. 373.

85. Haas, C.; Krinner, E.; Brischwein, K.; Hoffmann, P.; Lutterbuse, R.; Schlereth, B.; Kufer, P.; Baeuerle, P.A. Mode of cytotoxic action of $\mathrm{T}$ cell-engaging BiTE antibody MT110. Immunobiology 2009, 214, 441-453.

86. Loffler, A.; Kufer, P.; Lutterbuse, R.; Zettl, F.; Daniel, P.T.; Schwenkenbecher, J.M.; Riethmuller, G.; Dorken, B.; Bargou, R.C. A recombinant bispecific single-chain antibody, CD19 x CD3, induces rapid and high lymphoma-directed cytotoxicity by unstimulated T lymphocytes. Blood 2000, 95, 2098-2103.

87. Bargou, R.; Leo, E.; Zugmaier, G.; Klinger, M.; Goebeler, M.; Knop, S.; Noppeney, R.; Viardot, A.; Hess, G.; Schuler, M.; et al. Tumor regression in cancer patients by very low doses of a T cellengaging antibody. Science 2008, 321, 974-977.

88. Nagorsen, D.; Baeuerle, P.A. Immunomodulatory therapy of cancer with T cell-engaging BiTE antibody blinatumomab. Exp. Cell Res. 2011, 317, 1255-1260.

89. Topp, M.S.; Kufer, P.; Gokbuget, N.; Goebeler, M.; Klinger, M.; Neumann, S.; Horst, H.A.; Raff, T.; Viardot, A.; Schmid, M.; et al. Targeted therapy with the T-cell-engaging antibody blinatumomab of chemotherapy-refractory minimal residual disease in B-lineage acute lymphoblastic leukemia patients results in high response rate and prolonged leukemia-free survival. J. Clin. Oncol. 2011, 29, 2493-2498.

90. Handgretinger, R.; Zugmaier, G.; Henze, G.; Kreyenberg, H.; Lang, P.; von Stackelberg, A. Complete remission after blinatumomab-induced donor T-cell activation in three pediatric patients with post-transplant relapsed acute lymphoblastic leukemia. Leukemia 2011, 25, 181-184.

91. Pasquetto, M.V.; Vecchia, L.; Covini, D.; Digilio, R.; Scotti, C. Targeted drug delivery using immunoconjugates: principles and applications. J. Immunother. 2011, 34, 611-628.

92. Hopp, J.; Hornig, N.; Zettlitz, K.A.; Schwarz, A.; Fuss, N.; Muller, D.; Kontermann, R.E. The effects of affinity and valency of an albumin-binding domain (ABD) on the half-life of a singlechain diabody-ABD fusion protein. Protein Eng. Des. Sel. 2010, 23, 827-834.

93. Kellner, C.; Peipp, M.; Valerius, T. Effector cell recruitment by bispecific antibodies. In Bispecific Antibodies, 1st ed.; Kontermann, R.E., Ed.; Springer-Verlag: Berlin, Germany, 2011; p. 373. 
94. Bluemel, C.; Hausmann, S.; Fluhr, P.; Sriskandarajah, M.; Stallcup, W.B.; Baeuerle, P.A.; Kufer, P. Epitope distance to the target cell membrane and antigen size determine the potency of T cellmediated lysis by BiTE antibodies specific for a large melanoma surface antigen. Cancer Immunol. Immunother. 2010, 59, 1197-1209.

95. Brischwein, K.; Schlereth, B.; Guller, B.; Steiger, C.; Wolf, A.; Lutterbuese, R.; Offner, S.; Locher, M.; Urbig, T.; Raum, T.; et al. MT110: A novel bispecific single-chain antibody construct with high efficacy in eradicating established tumors. Mol. Immunol. 2006, 43, 1129-1143.

96. Cioffi, M.; Dorado, J.; Baeuerle, P.A.; Heeschen, C. EpCAM/CD3-Bispecific T-cell engaging antibody MT110 eliminates primary human pancreatic cancer stem cells. Clin. Cancer Res. 2012, $18,465-474$.

97. Kischel, R. Characterization in primates of MCSP- and CD33-specific human BiTE antibodies for treatment of Melanoma and AML. Proc. Am. Assoc. Cancer Res. 2008, 99, 2404.

98. Lutterbuese, R.; Raum, T.; Kischel, R.; Lutterbuese, P.; Schlereth, B.; Schaller, E.; Mangold, S.; Rau, D.; Meier, P.; Kiener, P.A.; et al. Potent control of tumor growth by CEA/CD3-bispecific single-chain antibody constructs that are not competitively inhibited by soluble CEA. J. Immunother. 2009, 32, 341-352.

99. Osada, T.; Hsu, D.; Hammond, S.; Hobeika, A.; Devi, G.; Clay, T.M.; Lyerly, H.K.; Morse, M.A. Metastatic colorectal cancer cells from patients previously treated with chemotherapy are sensitive to T-cell killing mediated by CEA/CD3-bispecific T-cell-engaging BiTE antibody. Br. J. Cancer 2010, 102, 124-133.

100. Torisu-Itakura, H.; Schoellhammer, H.F.; Sim, M.S.; Irie, R.F.; Hausmann, S.; Raum, T.; Baeuerle, P.A.; Morton, D.L. Redirected lysis of human melanoma cells by a MCSP/CD3bispecific BiTE antibody that engages patient-derived T cells. J. Immunother. 2011, 34, 597-605.

101. Jager, M.; Schoberth, A.; Ruf, P.; Hess, J.; Hennig, M.; Schmalfeldt, B.; Wimberger, P.; Strohlein, M.; Theissen, B.; Heiss, M.M.; Lindhofer, H. Immunomonitoring results of a phase II/III study of malignant ascites patients treated with the trifunctional antibody catumaxomab (anti-EpCAM $\mathrm{x}$ anti-CD3). Cancer Res. 2012, 72, 24-32.

102. Seimetz, D.; Lindhofer, H.; Bokemeyer, C. Development and approval of the trifunctional antibody catumaxomab (anti-EpCAM x anti-CD3) as a targeted cancer immunotherapy. Cancer Treat. Rev. 2010, 36, 458-467.

103. Kiewe, P.; Hasmuller, S.; Kahlert, S.; Heinrigs, M.; Rack, B.; Marme, A.; Korfel, A.; Jager, M.; Lindhofer, H.; Sommer, H.; et al. Phase I trial of the trifunctional anti-HER2 x anti-CD3 antibody ertumaxomab in metastatic breast cancer. Clin. Cancer Res. 2006, 12, 3085-3091.

104. Schroeder, P.; Lindemann, C.; Dettmar, K.; Brieger, J.; Gosepath, J.; Pogorzelski, B.; Seimetz, D.; Atz, J. Trifunctional antibodies induce efficient antitumour activity with immune cells from head and neck squamous cell carcinoma patients after radio-chemotherapy treatment. Clin. Transl. Oncol. 2011, 13, 889-898.

105. Zhang, T.; Sentman, C.L. Cancer immunotherapy using a bispecific NK receptor fusion protein that engages both T cells and tumor cells. Cancer Res. 2011, 71, 2066-2076.

106. Barber, A.; Rynda, A.; Sentman, C.L. Chimeric NKG2D expressing T cells eliminate immunosuppression and activate immunity within the ovarian tumor microenvironment. J. Immunol. 2009, 183, 6939-6947. 
107. Thakur, A.; Sorenson, C.; Norkina, O.; Schalk, D.; Ratanatharathorn, V.; Lum, L.G. Activated T cells from umbilical cord blood armed with anti-CD3 $\mathrm{x}$ anti-CD20 bispecific antibody mediate specific cytotoxicity against CD20+ targets with minimal allogeneic reactivity: A strategy for providing antitumor effects after cord blood transplants. Transfusion 2012, 52, 63-75.

108. Trinchieri, G. Biology of natural killer cells. Adv. Immunol. 1989, 47, 187-376.

109. Sanchez-Correa, B.; Morgado, S.; Gayoso, I.; Bergua, J.M.; Casado, J.G.; Arcos, M.J.; Bengochea, M.L.; Duran, E.; Solana, R.; Tarazona, R. Human NK cells in acute myeloid leukaemia patients: analysis of NK cell-activating receptors and their ligands. Cancer Immunol Immunother 2011, 60, 1195-1205.

110. Alderson, K.L.; Sondel, P.M. Clinical cancer therapy by NK cells via antibody-dependent cellmediated cytotoxicity. J. Biomed. Biotechnol. 2011, 2011, 379123.

111. Lundqvist, A.; Abrams, S.I.; Schrump, D.S.; Alvarez, G.; Suffredini, D.; Berg, M.; Childs, R. Bortezomib and depsipeptide sensitize tumors to tumor necrosis factor-related apoptosis-inducing ligand: A novel method to potentiate natural killer cell tumor cytotoxicity. Cancer Res. 2006, 66, 7317-7325.

112. Anfossi, N.; Andre, P.; Guia, S.; Falk, C.S.; Roetynck, S.; Stewart, C.A.; Breso, V.; Frassati, C.; Reviron, D.; Middleton, D.; et al. Human NK cell education by inhibitory receptors for MHC class I. Immunity 2006, 25, 331-342.

113. Leibson, P.J. Signal transduction during natural killer cell activation: Inside the mind of a killer. Immunity 1997, 6, 655-661.

114. Terunuma, H.; Deng, X.; Dewan, Z.; Fujimoto, S.; Yamamoto, N. Potential role of NK cells in the induction of immune responses: implications for NK cell-based immunotherapy for cancers and viral infections. Int. Rev. Immunol. 2008, 27, 93-110.

115. Jaiswal, S.; Chao, M.P.; Majeti, R.; Weissman, I.L. Macrophages as mediators of tumor immunosurveillance. Trends Immunol. 2010, 31, 212-219.

116. Lang, P.; Barbin, K.; Feuchtinger, T.; Greil, J.; Peipp, M.; Zunino, S.J.; Pfeiffer, M.; Handgretinger, R.; Niethammer, D.; Fey, G.H. Chimeric CD19 antibody mediates cytotoxic activity against leukemic blasts with effector cells from pediatric patients who received T-celldepleted allografts. Blood 2004, 103, 3982-3985.

117. Fuchs, A.; Colonna, M. The role of NK cell recognition of nectin and nectin-like proteins in tumor immunosurveillance. Semin. Cancer Biol. 2006, 16, 359-366.

118. Guerra, N.; Tan, Y.X.; Joncker, N.T.; Choy, A.; Gallardo, F.; Xiong, N.; Knoblaugh, S.; Cado, D.; Greenberg, N.M.; Raulet, D.H. NKG2D-deficient mice are defective in tumor surveillance in models of spontaneous malignancy. Immunity 2008, 28, 571-580.

119. Ljunggren, H.G.; Malmberg, K.J. Prospects for the use of NK cells in immunotherapy of human cancer. Nat. Rev. Immunol. 2007, 7, 329-339.

120. Lang, P.; Pfeiffer, M.; Teltschik, H.M.; Schlegel, P.; Feuchtinger, T.; Ebinger, M.; Klingebiel, T.; Bader, P.; Schlegel, P.G.; Beck, J.; et al. Natural killer cell activity influences outcome after T cell depleted stem cell transplantation from matched unrelated and haploidentical donors. Best Pract. Res. Clin. Haematol. 2011, 24, 403-411. 
121. Locatelli, F.; Vinti, L.; Palumbo, G.; Rossi, F.; Bertaina, A.; Mastronuzzi, A.; Bernardo, M.E.; Rutella, S.; Dellabona, P.; Giorgiani, G.; et al. Strategies to optimize the outcome of children given T-cell depleted HLA-haploidentical hematopoietic stem cell transplantation. Best Pract. Res. Clin. Haematol. 2011, 24, 339-349.

122. Pende, D.; Marcenaro, S.; Falco, M.; Martini, S.; Bernardo, M.E.; Montagna, D.; Romeo, E.; Cognet, C.; Martinetti, M.; Maccario, R.; et al. Anti-leukemia activity of alloreactive NK cells in KIR ligand-mismatched haploidentical HSCT for pediatric patients: evaluation of the functional role of activating KIR and redefinition of inhibitory KIR specificity. Blood 2009, 113, 3119-3129.

123. Ruggeri, L.; Mancusi, A.; Capanni, M.; Urbani, E.; Carotti, A.; Aloisi, T.; Stern, M.; Pende, D.; Perruccio, K.; Burchielli, E.; et al. Donor natural killer cell allorecognition of missing self in haploidentical hematopoietic transplantation for acute myeloid leukemia: Challenging its predictive value. Blood 2007, 110, 433-440.

124. Velardi, A.; Ruggeri, L.; Mancusi, A.; Aversa, F.; Christiansen, F.T. Natural killer cell allorecognition of missing self in allogeneic hematopoietic transplantation: a tool for immunotherapy of leukemia. Curr. Opin. Immunol. 2009, 21, 525-530.

125. Kitamoto, K.; Machida, Y.; Uchida, J.; Izumi, Y.; Shiota, M.; Nakao, T.; Iwao, H.; Yukimura, T.; Nakatani, T.; Miura, K. Effects of liposome clodronate on renal leukocyte populations and renal fibrosis in murine obstructive nephropathy. J. Pharmacol. Sci. 2009, 111, 285-292.

126. Giorgini, A.; Brown, H.J.; Lock, H.R.; Nimmerjahn, F.; Ravetch, J.V.; Verbeek, J.S.; Sacks, S.H.; Robson, M.G. Fc gamma RIII and Fc gamma RIV are indispensable for acute glomerular inflammation induced by switch variant monoclonal antibodies. J. Immunol. 2008, 181, 8745-8752.

127. Hamerman, J.A.; Ogasawara, K.; Lanier, L.L. Cutting edge: Toll-like receptor signaling in macrophages induces ligands for the NKG2D receptor. J. Immunol. 2004, 172, 2001-2005.

128. Sun, J.C.; Lanier, L.L. NK cell development, homeostasis and function: Parallels with CD8 T cells. Nat. Rev. Immunol. 2011, 11, 645-657.

129. Cartron, G.; Dacheux, L.; Salles, G.; Solal-Celigny, P.; Bardos, P.; Colombat, P.; Watier, H. Therapeutic activity of humanized anti-CD20 monoclonal antibody and polymorphism in IgG Fc receptor FcgammaRIIIa gene. Blood 2002, 99, 754-758.

130. Weng, W.K.; Levy, R. Two immunoglobulin G fragment C receptor polymorphisms independently predict response to rituximab in patients with follicular lymphoma. J. Clin. Oncol. 2003, 21, 3940-3947.

131. Bibeau, F.; Lopez-Crapez, E.; Di Fiore, F.; Thezenas, S.; Ychou, M.; Blanchard, F.; Lamy, A.; Penault-Llorca, F.; Frebourg, T.; Michel, P.; et al. Impact of Fc \{gamma\}RIIa-Fc\{gamma\}RIIIa polymorphisms and KRAS mutations on the clinical outcome of patients with metastatic colorectal cancer treated with cetuximab plus irinotecan. J. Clin. Oncol. 2009, 27, 1122-1129.

132. Musolino, A.; Naldi, N.; Bortesi, B.; Pezzuolo, D.; Capelletti, M.; Missale, G.; Laccabue, D.; Zerbini, A.; Camisa, R.; Bisagni, G.; et al. Immunoglobulin G fragment $\mathrm{C}$ receptor polymorphisms and clinical efficacy of trastuzumab-based therapy in patients with HER-2/neupositive metastatic breast cancer. J. Clin. Oncol. 2008, 26, 1789-1796.

133. Elsasser, D.; Stadick, H.; Stark, S.; Van de Winkel, J.G.; Gramatzki, M.; Schrott, K.M.; Valerius, T.; Schafhauser, W. Preclinical studies combining bispecific antibodies with cytokine-stimulated effector cells for immunotherapy of renal cell carcinoma. Anticancer Res. 1999, 19, 1525-1528. 
134. Weiner, L.M.; Holmes, M.; Adams, G.P.; LaCreta, F.; Watts, P.; Garcia de Palazzo, I. A human tumor xenograft model of therapy with a bispecific monoclonal antibody targeting c-erbB-2 and CD16. Cancer Res. 1993, 53, 94-100.

135. Weiner, L.M.; Holmes, M.; Richeson, A.; Godwin, A.; Adams, G.P.; Hsieh-Ma, S.T.; Ring, D.B.; Alpaugh, R.K. Binding and cytotoxicity characteristics of the bispecific murine monoclonal antibody 2B1. J. Immunol. 1993, 151, 2877-2886.

136. Lu, H.; Shi, M.; Wang, M.; Xie, Z.; Hu, M.; Yu, M.; Shen, B.; Ma, Y.; Guo, N. In vitro and in vivo antitumor effect of a trivalent bispecific antibody targeting ErbB2 and CD16. Cancer Biol. Ther. 2008, 7, 1744-1750.

137. Bruenke, J.; Fischer, B.; Barbin, K.; Schreiter, K.; Wachter, Y.; Mahr, K.; Titgemeyer, F.; Niederweis, M.; Peipp, M.; Zunino, S.J.; et al. A recombinant bispecific single-chain Fv antibody against HLA class II and FcgammaRIII (CD16) triggers effective lysis of lymphoma cells. Br. J. Haematol. 2004, 125, 167-179.

138. Singer, H.; Kellner, C.; Lanig, H.; Aigner, M.; Stockmeyer, B.; Oduncu, F.; Schwemmlein, M.; Stein, C.; Mentz, K.; Mackensen, A.; Fey, G.H. Effective elimination of acute myeloid leukemic cells by recombinant bispecific antibody derivatives directed against CD33 and CD16. J. Immunother. 2010, 33, 599-608.

139. Schubert, I.; Kellner, C.; Stein, C.; Kugler, M.; Schwenkert, M.; Saul, D.; Mentz, K.; Singer, H.; Stockmeyer, B.; Hillen, W.; et al. A single-chain triplebody with specificity for CD19 and CD33 mediates effective lysis of mixed lineage leukemia cells by dual targeting. MAbs 2011, 3, 21-30.

140. Schubert, I.; Kellner, C.; Stein, C.; Kugler, M.; Schwenkert, M.; Saul, D.; Stockmeyer, B.; Berens, C.; Oduncu, F.S.; Mackensen, A.; et al. A recombinant triplebody with specificity for CD19 and HLA-DR mediates preferential binding to antigen double-positive cells by dual-targeting. MAbs 2012, 4, 45-56.

141. Schubert, I.; Stein, C.; Fey, G.H. Dual-Targeting for the Elimination of Cancer Cells with Increased Selectivity. Antibodies 2012, 1, 2-18.

142. Stein, C.; Schubert, I.; Fey, G.H. Trivalent and trispecific antibody derivatives for cancer therapy. In Bispecific Antibodies, 1st ed; Kontermann, R.E., Ed.; Springer-Verlag: Berlin, Germany, 2011; p. 373.

143. Kellner, C.; Bruenke, J.; Horner, H.; Schubert, J.; Schwenkert, M.; Mentz, K.; Barbin, K.; Stein, C.; Peipp, M.; Stockmeyer, B.; et al. Heterodimeric bispecific antibody-derivatives against CD19 and CD16 induce effective antibody-dependent cellular cytotoxicity against B-lymphoid tumor cells. Cancer Lett. 2011, 303, 128-139.

144. Johnson, S.; Burke, S.; Huang, L.; Gorlatov, S.; Li, H.; Wang, W.; Zhang, W.; Tuaillon, N.; Rainey, J.; Barat, B.; et al. Effector cell recruitment with novel Fv-based dual-affinity re-targeting protein leads to potent tumor cytolysis and in vivo B-cell depletion. J. Mol. Biol. 2010, 399, 436-449.

145. Arndt, M.A.; Krauss, J.; Kipriyanov, S.M.; Pfreundschuh, M.; Little, M. A bispecific diabody that mediates natural killer cell cytotoxicity against xenotransplantated human Hodgkin's tumors. Blood 1999, 94, 2562-2568. 
146. Kipriyanov, S.M.; Cochlovius, B.; Schafer, H.J.; Moldenhauer, G.; Bahre, A.; Le Gall, F.; Knackmuss, S.; Little, M. Synergistic antitumor effect of bispecific CD19 x CD3 and CD19 x CD16 diabodies in a preclinical model of non-Hodgkin's lymphoma. J. Immunol. 2002, 169, $137-44$.

147. Schlenzka, J.; Moehler, T.M.; Kipriyanov, S.M.; Kornacker, M.; Benner, A.; Bahre, A.; Stassar, M.J.; Schafer, H.J.; Little, M.; Goldschmidt, H.; et al. Combined effect of recombinant CD19 x CD16 diabody and thalidomide in a preclinical model of human B cell lymphoma. Anticancer Drugs 2004, 15, 915-919.

148. Champsaur, M.; Lanier, L.L. Effect of NKG2D ligand expression on host immune responses. Immunol. Rev. 2010, 235, 267-285.

149. Germain, C.; Larbouret, C.; Cesson, V.; Donda, A.; Held, W.; Mach, J.P.; Pelegrin, A.; Robert, B. MHC class I-related chain A conjugated to antitumor antibodies can sensitize tumor cells to specific lysis by natural killer cells. Clin. Cancer Res. 2005, 11, 7516-7522.

150. Dhodapkar, M.V.; Sanderson, R.D. Syndecan-1 (CD 138) in myeloma and lymphoid malignancies: A multifunctional regulator of cell behavior within the tumor microenvironment. Leuk. Lymphoma 1999, 34, 35-43.

151. Dhodapkar, K.M.; Krasovsky, J.; Williamson, B.; Dhodapkar, M.V. Antitumor monoclonal antibodies enhance cross-presentation ofcCellular antigens and the generation of myelomaspecific killer T cells by dendritic cells. J. Exp. Med. 2002, 195, 125-133.

152. von Strandmann, E.P.; Hansen, H.P.; Reiners, K.S.; Schnell, R.; Borchmann, P.; Merkert, S.; Simhadri, V.R.; Draube, A.; Reiser, M.; Purr, I.; et al. A novel bispecific protein (ULBP2-BB4) targeting the NKG2D receptor on natural killer (NK) cells and CD138 activates NK cells and has potent antitumor activity against human multiple myeloma in vitro and in vivo. Blood 2006, 107, 1955-1962.

153. Cho, H.M.; Rosenblatt, J.D.; Tolba, K.; Shin, S.J.; Shin, D.S.; Calfa, C.; Zhang, Y.; Shin, S.U. Delivery of NKG2D ligand using an anti-HER2 antibody-NKG2D ligand fusion protein results in an enhanced innate and adaptive antitumor response. Cancer Res. 2010, 70, 10121-10130.

154. Jachimowicz, R.D.; Fracasso, G.; Yazaki, P.J.; Power, B.E.; Borchmann, P.; Engert, A.; Hansen, H.P.; Reiners, K.S.; Marie, M.; von Strandmann, E.P.; et al. Induction of in vitro and in vivo NK cell cytotoxicity using high-avidity immunoligands targeting prostate-specific membrane antigen in prostate carcinoma. Mol. Cancer Ther. 2011, 10, 1036-1045.

155. Kellner, C.; Hallack, D.; Glorius, P.; Staudinger, M.; Mohseni Nodehi, S.; de Weers, M.; van de Winkel, J.G.; Parren, P.W.; Stauch, M.; Valerius, T.; et al. Fusion proteins between ligands for NKG2D and CD20-directed single-chain variable fragments sensitize lymphoma cells for natural killer cell-mediated lysis and enhance antibody-dependent cellular cytotoxicity. Leukemia 2011, $26,830-834$.

156. Barkholt, L.; Alici, E.; Conrad, R.; Sutlu, T.; Gilljam, M.; Stellan, B.; Christensson, B.; Guven, H.; Bjorkstrom, N.K.; Soderdahl, G.; et al. Safety analysis of ex vivo-expanded NK and NK-like T cells administered to cancer patients: A phase I clinical study. Immunotherapy 2009, 1, 753-764.

157. Klingemann, H. G.; Martinson, J. Ex vivo expansion of natural killer cells for clinical applications. Cytotherapy 2004, 6, 15-22. 
158. Koehl, U.; Esser, R.; Zimmermann, S.; Tonn, T.; Kotchetkov, R.; Bartling, T.; Sorensen, J.; Gruttner, H.P.; Bader, P.; Seifried, E.; et al. Ex vivo expansion of highly purified NK cells for immunotherapy after haploidentical stem cell transplantation in children. Klin. Padiatr. 2005, 217, 345-350.

159. Schubert, I. Department Biology, University of Erlangen-Nuremberg. 2012, unpublished work.

160. Alici, E.; Sutlu, T.; Bjorkstrand, B.; Gilljam, M.; Stellan, B.; Nahi, H.; Quezada, H.C.; Gahrton, G.; Ljunggren, H.G.; Dilber, M.S. Autologous antitumor activity by NK cells expanded from myeloma patients using GMP-compliant components. Blood 2008, 111, 3155-3162.

(C) 2012 by the authors; licensee MDPI, Basel, Switzerland. This article is an open access article distributed under the terms and conditions of the Creative Commons Attribution license (http://creativecommons.org/licenses/by/3.0/). 